NBSIR 77-1198 (R)

\title{
Examination of 3/4 Inch Steel Pipe Natural Gas Service Lines, Delmarva Power and Light Company, Wilmington, Delaware
}

T. Robert Shives

Mechanical Properties Section Metallurgy Division Institute for Materials Research National Bureau of Standards

Washington, D. C. 20234

Failure Analysis Report

December 1976

\section{Prepared for}

Office of Pipeline Safety Operations Department of Transportation Washington, D. C. 20590 

EXAMINATION OF $3 / 4$ INCH STEEL

PIPE NATURAL GAS SERVICE LINES.

DELMARVA POWER AND LIGHT

COMPANY, WILMINGTON,

DELAWARE

T. Robert Shives

Mechanical Properties Section

Metallurgy Division

Institute for Materials Research

National Bureau of Standards

Washington, D. C. 20234

Failure Analysis Report

December 1976

Prepared for

Office of Pipeline Safety Operations

Department of Transportation

Washington, D. C. 20590

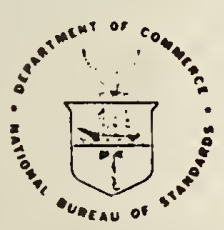

U.S. DEPARTMENT OF COMMERCE, Elliot L. Richardson, Secretary

Edward O. Vetter, Under Secretary

Dr. Betsy Ancker-Johnson. Assistant Secretary for Science and Technology

NATIONAL BUREAU OF STANDARDS, Ernest Ambler, Acting Director 

1. INTRODUCTION

1.1 Reference

1.2 Background Information

1.3 Parts Submitted

2. PURPOSE

3. REPORT FORMAT

4. RESULTS OF EXAMINATIONS AND TESTS

4.1 Pipe Sample from 13 Clayton Court 3

4.1.1 Visual and Macroscopic Examination 3

4.1.2 Wal1 Thickness Measurements 4

4.1.3 Metallographic Examination 4

4.1.4 Hardness Measurements 5

4.2 Pipe Samples Other Than That From 13 Clayton Court 5

4.2.1 Visual and Macroscopic Examination in the As Received at NBS Condition and After Cross Sectioning

4.2.2 Leak Tests 7

4.2.3 Pipe Condition After Rust Remova1 . 7

4.2.4 Wall Thickness Measurements $\quad 8$

4.2.5 Metallographic Examination 8

4.2.6 Hardness Measurements 9

5. DISCUSSION 9

5.1 Pipe Sample From 13 Clayton Court 9 
Table of Contents (continued)

Page

5.2 Pipe Samples other Than That From 13 Clayton Court

5.3 Genera1 Discussion

6. CONCLUSIONS

6.1 Pipe Sample From 13 Clayton Court

6.2 Pipe Samples Other Than That From 13 Clayton Court

7. ACKNOWLEDGEMENT

REFERENCE

TABLES

1. Results of Wa11 Thickness Measurements.

2. Results of Hardness Measurements.

3. Cross Sectional Deformation at the Bend in the Pipe.

\section{FIGURES}

1. Steel pipe natural gas service line from 13 Clayton Court, Edgemoor Gardens, Wilmington, Delaware as received at NBS.

2. Thirteen steel pipe natural gas service lines from Edgemoor Gardens, Wilmington, Delaware as received at NBS.

3. Four views around the circumference of the pipe from 13 Clayton Court showing extensive corrosion.

4. Cross section through severely corroded region of pipe from 13 Clayton Court.

5. Unetched cross section through pipe from 13 Clayton Court.

6. Etched cross section through pipe from 13 Clayton Court.

7. Pipe from 1 Clayton Ct.

8. Pipe from 2 Clayton $\mathrm{Ct}$.

9. Pipe from 5 clayton $\mathrm{Ct}$. 


\section{FIGURES (continued)}

10. Pipe from 6 Clayton $C t$.

11. Pipe from 7 Clayton Ct.

12. Pipe from 8 clayton Ct.

13. Pipe from 9 clayton Court.

14. Pipe from 12 Clayton Ct.

15. Pipe from 31 s. Bennywe11.

16. Pipe identified as 7 .

17. Pipe identified as 10 .

18. Pipe from $13 \mathrm{~s}$. Cannon Dr.

19. Pipe from $18 \mathrm{~s}$. Cannon.

20. Pipe from $18 \mathrm{~S}$. Cannon before and after cleaning.

21. Pipe from 31 S. Bennywell before and after cleaning.

22. As-polished cross section through the pipe from 8 Clayton Ct. showing inclusion content representative of the sections examined.

23. As-polished cross section through the pipe from $31 \mathrm{~S}$. Bennywell showing porosity.

24. Etched cross section through the bend of the pipe sample from 8 Clayton Ct. showing cracking of the weld at the inside of the pipe.

25. Etched cross section through pipe sample designated 10.

26. As-polished cross section through pipe sample from $31 \mathrm{~S}$. Bennywell showing corrosion product on the inside of the pipe.

27. Etched cross section through pipe sample from 8 clayton Ct. showing microstructure consisting of ferrite and a small amount of pearlite.

28. Etched cross section through pipe sample designated 7 showing microstructure consisting of ferrite and a small amount of pearlite.

29. Etched cross section through pipe sample designated 10 showing the microstructure at the weld and on both sides of the weld.

30. Etched cross section through pipe sample from 8 Clayton $C$. showing decarburization adjacent to the pipe surface in a slightly corroded region. 


\section{SUMMARY}

The Office of Pipeline Safety Operations requested that the NBS Mechanical Properties Section examine fourteen $3 / 4$ inch diameter steel pipe natural gas service lines from Edgemoor Gardens, Wilmington, Delaware. The submitted samples had all been installed in crawl spaces under houses. An explosion had been attributed to the ignition of gas leaking from one of these pipes. All of the pipe samples exhibited corrosion to some extent. Two samples, including the one reportedly involved in the explosion, had been perforated. Many others were severely corroded. A reportedly high concentration of water vapor in the poorly ventilated crawl spaces is suggested as the source of the corroding medium. Measurements in essentially uncorroded regions indicated that the original pipe wall thickness would meet current (1976) ASTM specifications. All but one of the longitudinal seam welds appeared to be in satisfactory condition. The unsatisfactory weld was cracked at a bend in the pipe where there was a considerable amount of

ross sectional deformation. Several samples exhibited cross sectional deformation at the bend. The hardness and microstructure of the weld and parent materials appeared to be compatible. The microstructure of all the samples examined appeared to be satisfactory except for one sample that exhibited a large amount of porosity. All except the two perforated samples withstood a leak test at 30 psig natural gas. 
Examination of $3 / 4$ Inch Steel Pipe Natural Gas Service Lines, Delmarva Power and Light Company, Wilmington, Delaware

\section{INTRODUCTION}

\subsection{Reference}

Office of Pipeline Safety Operations, Materials Transportation Bureau, Department of Transportation, Washington, D.C. 20590. This investigation was conducted at the request of $\mathrm{Mr}$. Cesar DeLeon, Acting Director of the Office of Pipeline Safety Operations, under agreement number DOT-AS-60053. The request letter was dated July 1, 1976.

\subsection{Background Information}

The information in this section was furnished by $\mathrm{Mr}$. Lance $\mathrm{F}$. Heverly of the Office of Pipeline Safety Operations and Messrs. J. Benjamin Roy, Jr. and Daniel R. Kiley, Fire Marshal and Deputy Fire Marshal, respectively, of the State of Delaware.

On February 25, 1976, there was an explosion at 13 Clayton Court, Edgemoor Gardens, Wilmington, Delaware. The explosion was attributed to the ignition of an accumulation of natural gas that had escaped from a $3 / 4$ inch diameter steel pipe gas service line in the crawl space under the house at 13 Clayton Court.

The service line at 13 Clayton Court, as well as those at other houses in the Edgemoor Gardens development, entered the crawl space by passing horizontally through the foundation wall of the house. The pipe then turned $90^{\circ}$ to a vertical position and then passed through a concrete slab floor to the house above.

It was reported that the crawl spaces under the residences in the Edgemoor Gardens development were poorly ventilated and damp.

Schedule 80 , extra heavy wa11, 1ongitudinally seam welded black steel pipe had been used for the service lines. The diameter of the pipe was $3 / 4$ inch. The lines were installed in 1942 .

\subsection{Parts Submitted}

Two pieces of $3 / 4$ inch diameter steel natural gas service line pipe from 13 Clayton Court, Edgemoor Gardens, Wilmington, Delaware were delivered to the National Bureau of Standards (NBS) Mechanical Properties Section on March 2, 1976 by J. Benjamin Roy, Jr., and Daniel R. Kiley, Fire Marshal and Leputy Fire Marshal, respectively, of the State of Delaware. Present at the time of the delivery, in addition to Messrs. Roy and Kiley, were Lance F. Heverly and Robert F. Langley of the Office of Pipeline Safety Operations, and Bruce W. Christ and T. Robert Shives of the NBS Mechanical Properties Section. 
These two pieces of pipe are shown in figure 1 as received at NBS. As described by the Delaware Fire Marshal's Office, item 1 (bottom piece in figure 1) was about $381 / 2$ inches in total length with a $90^{\circ}$ bend having one leg approximately 12 inches in length and the other leg approximately $26 \mathrm{l} / 2$ inches in length. Item 2 (top piece in figure 1) was approximately 17 inches in length. Item 2 had been separated from item 1 by sawing at the scene. At the top of item 2 (at the right in figure 1) is the service cock for the gas system at 13 Clayton Court. A sleeve was also attached to item 2 where it passed through the concrete floor separating the house from the crawl space under it.

On March 3, 1976, thirteen additional pieces of $3 / 4$ inch diameter steel pipe natural gas service line were delivered by Lance F. Heverly to the NBS Mechanical Properties Section. All of these pipe samples were from crawl spaces under houses in Edgemoor Gardens in Wilmington, Delaware. These pieces of pipe, shown in figure 2 as received at NBS had the following identification tags attached to them.

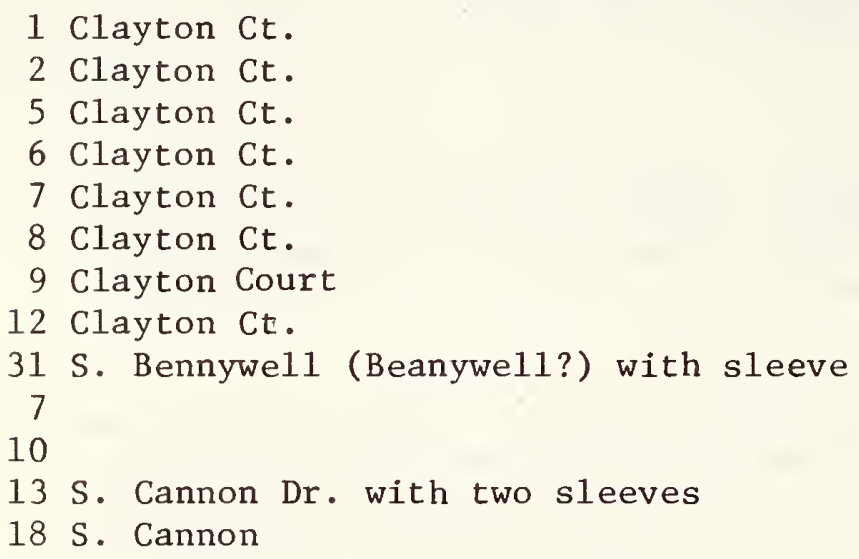

Each of the above pieces of service line pipe had a $90^{\circ}$ bend, but the radius of curvature of the bend differed among the various pieces. The total length of the various pieces also varied.

In addition to the pipe and sleeves, one repair coupling was submitted.

\section{PURPOSE}

The Office of Pipeline Safety Operations requested that the NBS Mechanical Properties Section perform the following tasks:

1. Establish and maintain sample identification and custodial record for documentation.

2. Provide six documentary photographs showing the physical condition of the failed pieces as soon as practical to OPSO for its information and for trąnsmittal to the Delaware State Fire Marshal. 
3. Prepare similar documentary photographs of the 13 samples submitted on March 3, 1976, before and after rust removal.

4. Make other photographic representations as deemed appropriate from examination or testing.

5. Test selected samples from the 13 additional pieces prior to rust removal for leakage with natural gas at 30 psig and, if found to be leaking, determine total and unit length average leakage rates at 20 and 30 psig.

6. Determine original wall thickness of the failed pieces and other samples.

7. Remove rust scale from selected samples of the 13 samples delivered on March 3 and determine the remaining wall thickness at representative locations of approximate maximum and average pitting.

8. Inspect pieces and samples for any apparent mechanical damage, including cross sectional deformation, due to bending and incipient or existing opening of the longitudinal seam weld, if any. Evaluate the effect on the serviceability of the pipe where applicable.

9. Cut and macroscopically inspect specimens of fracture face of cracks and breaks. Based on this inspection, perform metallographic analysis as deemed necessary.

10. Determine such other tests or analyses which appear necessary or desirable from the foregoing examination or other evaluation. Advise OPSO accordingly and perform same pursuant to concurrence.

In compliance with item 2 above, documentary photographs of the pipe samples from 13 Clayton Court were sent to the Office of Pipeline Safety Operations on July 14, 1976.

\section{REPORT FORMAT}

In this report, the results of the examination of the pipe from 13 Clayton Court will be presented separately from the results of the examination of the other 13 service lines.

\section{RESULTS OF EXAMINATIONS AND TESTS}

4.1 Pipe Sample from 13 Clayton Court

\subsubsection{Visual and Macroscopic Examination}

Both pieces of pipe from 13 Clayton Court exhibited evidence of both general and pitting corrosion. Corrosion was essentially superficial near the top of the pipe close to the service cock. The severity of the 
corrosive attack increased with the distance from the top of the pipe. It was most severe in the region of the $90^{\circ}$ bend, with several perforations being evident. Some of the results of corrosion can be seen in figure 1 . In figure 3, four higher magnification views of the circumference of the , ipe in the vicinity of arrow $A$ in figure 1 show corrosion at the bend where the pipe has been perforated.

Arrows $B$ in figure 1 indicate two areas of mechanical damage. The damage has the appearance of rather shallow saw cuts. The bottoms of both of these regions exhibited some shiny metal when submitted to NBS, indicating that the damage may have occurred shortly before the pipe was submitted. Neither of these regions of mechanical damage would be expected to have a significant adverse effect on the integrity of the pipe.

\subsubsection{Wa11 Thickness Measurements}

The approximate original wall thickness of the pipe was determined at a cross section through one of the regions least affected by corrosion. As given in Table 1 , the average of four measurements was 0.155 inch and the range was 0.152 to 0.156 inch. The specified nominal wall thickness for schedule $803 / 4$ inch diameter steel pipe is 0.154 inch! The minimum acceptable wall thickness is 0.135 inch!

In order to determine the wall thickness in a severely corroded region, the pipe was sectioned through the region of perforations in the vicinity of arrow A in figure 1. This cross section is shown in figure 4. The wa11 thickness ranged from zero at a perforation to 0.139 inch. The corrosion was non-uniform at this cross section, with the maximum wall thickness being greater than the minimum required in reference 1 .

As can be seen in figure 4, there is no apparent cross sectional deformation at the part of the bend where the cross section was taken. There did not appear to be any significant deformation anywhere else in the bend, either.

\subsubsection{Metallographic Examination}

The cross section shown in figure 4 was examined metallographically. Part of the cross section is shown in figure 5 in the unetched condition. The steel is relatively free of inclusions and there is no evidence of norosity. There is a heavy layer of corrosion product on the outer surface if the pipe. The inside surface of the pipe is not shown, but the corrosion was negligible.

Part of the cross section is shown at a higher magnification in the etched condition in figure 6. The microstructure consists primarily of ferrite with a very small amount of pearlite. 


\subsubsection{Hardness Measurements}

Rockwell B (HRB) hardness measurements were made on the cross section where the "original" wall thickness measurements were made. The results of measurements away from the weld ranged from HRB 67 to 72 . The average was HRB 69 as indicated in Table 2.

\subsection{Pipe Samples Other Than That From 13 Clayton Court}

\subsubsection{Visual and Macroscopic Examination in the As Received at NBS Condition and After Cross Sectioning}

Although the welded longitudinal seam was quite obvious on the surface of some of the pipe samples, in no case, with visual or macroscopic examination, did the welded seam appear to be open or opening. (As discussed later, metallographic examination revealed an apparent crack in the weld in one sample.) Corrosion was no more severe at the welds than elsewhere.

Several of the samples exhibited cross sectional deformation at the bend. This deformation, expressed as the difference between the maximum and minimum inside diameter of the pipe at a cross section through the bend, is shown in Table 3 for some of the samples that exhibited the greatest amount of cross sectional deformation.

Because of differences in condition among the various pipe samples, each sample will be described individually.

1 Clayton Ct. There was mild general corrosion over the entire submitted pipe length. Corrosion was somewhat more severe at the bend (figure 7a) than elsewhere. No significant mechanical damage was observed. Some cross sectional deformation was evident at the bend (figure $7 \mathrm{~b}$ ).

2 Clayton $C t$. There was moderate general corrosion over the entire submitted pipe length and there was significant pitting corrosion both at the bend (figure 8) and away from the bend. No significant mechanical damage or cross sectional deformation was observed.

5 Clayton $\mathrm{Ct}$. There was slight general corrosion over the entire submitted pipe length and a small amount of moderate pitting at the bend (figure 9a). No significant mechanical damage was observed. Some cross sectional deformation at the bend was evident (figure 9b).

6 Clayton $\mathrm{Ct}$. There was mild general corrosion over the entire submitted pipe length. Pitting was significant at the bend (figure 10a). In addition, in a region about 8 inches from the bend, corrosion was severe (figure 10b). A cross section through the pipe in this region is shown in figure $10 \mathrm{c}$. The arrow in figure $10 \mathrm{a}$ indicates a cut in the pipe probably made by a pipe cutting tool. This cut was quite deep and had penetrated the 
entire wall thickness in at least one place. This mechanical damage appeared to be recent and may have been done when the pipe was removed from service. No other significant mechanical damage was observed. Cross sectional deformation was insignificant.

7 Clayton $\mathrm{Ct}$. There was mild general corrosion over the entire submitted pipe length with some relatively mild pitting at the bend (figure 11a). No significant mechanical damage was observed, although there were what appeared to be some shallow pipe wrench marks (not shown in the figure). Some cross sectional deformation at the bend was evident (figure 11b).

8 Clayton $\mathrm{Ct}$. There was significant general corrosion and some pitting over the entire submitted pipe length (figure 12a). Corrosion was more severe at one end of the bend than elsewhere (figures $12 \mathrm{~b}$ and $12 \mathrm{c}$ ). No significant mechanical damage was observed. Some cross sectional deformation at the bend was evident (figure 12d).

9 Clayton Court. There was slight general corrosion over the entire submitted pipe length (figure 13a). Corrosion was somewhat more severe with pitting at the bend. No significant mechanical damage was observed. There was some cross sectional deformation at the bend (figure 13b).

12 Clayton Ct. There was a significant amount of corrosion over the entire submitted pipe length (figure 14a). Some scale and pitting were evident. Corrosion did not appear to be more severe at the bend than elsewhere. Neither any significant mechanical damage nor cross sectional deformation was observed (figure 14b).

31 S. Bennywe11(?). There was moderate general corrosion and significant pitting over the entire submitted length of pipe not covered by the sleeve (figure 15a). The cross section shown in figure $15 \mathrm{~b}$ was taken through one of the most severely corroded regions, but not at the bend. Some porosity was observed at this cross section and at other cross sections from this pipe sample. Apparently, there was a line of porosity extending over at least the entire submitted length of pipe that had not been covered by the sleeve. No significant mechanical damage was evident. There was a slight amount of cross sectional deformation at the bend.

7. Corrosion was mild away from the bend. At the bend, however, corrosion was very severe with a large loss of material and perforation of the pipe (figure 16a). At the location of the perforation, the pipe appears to have suffered some mechanical damage, manifested in the form of a depression in the pipe. A cross section through the pipe at the depression is shown in figure 16b. It is not clear when the depression was formed. If it was formed after corrosion 
had thinned the pipe wall to the point shown, it would have been relatively easy to push the pipe in to form the depression. No other significant mechanical damage was observed. Significant cross sectional deformation was observed at the bend, although this deformation is not evident in figure $16 \mathrm{~b}$.

10. Corrosion was severe in the vicinity of the bend (figure 17a). There were large diameter, round pits. Corrosion, in general, was less severe as the distance from the bend increased, although there were some large pits well removed from the bend.

Part of the pipe that had been covered with the sleeve was examined. Corrosion was very slight where the sleeve had been except near the end of the sleeve where some pitting was observed (figure $17 \mathrm{~b}$ ). No significant mechanical damage or cross sectional deformation was observed (figure 17c).

13 S. Cannon Dr. There was a considerable amount of soil adhering to this pipe sample, indicating that, unlike the other samples, it had been under a soil cover. Both general corrosion and pitting were rather severe in the relatively short length of pipe exposed between the two sleeves (figure 18a). A cross section through one of the more severely corroded regions is shown in figure $18 \mathrm{~b}$. Mechanical damage and cross sectional deformation were insignificant.

18 S. Cannon. General corrosion appeared as a gradient ranging from slight away from the bend to severe approaching the bend (figure 19a). There was severe pitting at the bend and adjacent to the sleeve. No significant mechanical damage or cross sectional deformation was observed (figure 19b).

\subsubsection{Leak Tests}

Except for the pipe sample identified as "7", all of the pipe samples submitted on March 3, 1976, were leak tested. Pipe sample 7 was not tested because it had an obvious perforation. The leak tests were made at a pressure of 30 psig with natural gas used as the pressurizing medium.

Each pipe sample was tested individually. Appropriate fittings were affixed to the pipe ends for admitting gas and sealing the system from the atmosphere. Before being pressurized, the pipe samples were flushed with natural gas. After being pressurized, the pressure was monitored for at least three hours. No leak was observed in any of the samples.

\subsubsection{Pipe Condition After Rust Removal}

Selected parts of several of the submitted pipe samples were cleaned of rust (and adhering soil where necessary) with a wire wheel in order to facilitate the examination of the pipe surfaces with the rust 
removed. The parts selected for cleaning were those that exhibited the severest corrosion. Two representative examples of pipe samples both before and after cleaning are shown in figures 20 and 21 . In no case did the condition of the pipe appear to be significantly altered by the removal of the rust. Therefore, except for the change in appearance due to the loss of the corrosion product itself, the descriptions of the pipe samples presented in Section 4.2.1 of this report apply equally well to the cleaned pipe. Because there appeared to be no significant change in condition, the cleaned pipes were not leak tested.

\subsubsection{Wall Thickness Measurements}

Wall thickness measurements of each of the thirteen pipe samples other than that from 13 Clayton Court were made at a cross section through the pipe in a region least affected by corrosion. The wall thickness at these cross sections very closely approximated the original wall thickness of the pipe. Four measurements about $90^{\circ}$ apart were made at each cross section. The average measurement and the range for each pipe sample are given in Table 1. All measurements were greater than the 0.135 inch minimum acceptable wall thickness for schedule $80 \mathrm{pipe}^{1}$.

The minimum wall thickness was determined for each of the same 13 pipe samples at a cross section taken where the corrosion appeared to be the most severe. These cross sections are shown in figures 7 through 19. The results of the minimum wall thickness measurements are given in Table 1. In all cases except for the samples from 1 clayton $\mathrm{Ct}$. and 5 Clayton Ct., the minimum wall thickness was less than the specified minimum of 0.135 inch1.

\subsubsection{Metallographic Examination}

Several of the cross sections where the minimum wall thickness measurements were made or where cross sectional deformation was determined were examined metallographically. For the most part, the material was rather clean and free of porosity. An example representative of the inclusion content of the samples examined is shown in figure 22 .

In all the cross sections examined, the only significant porosity observed was in the pipe sample from $31 \mathrm{~S}$. Bennywell. This porosity was referred to earlier and can be seen in figure 15b. Part of the cross section shown in figure $15 \mathrm{~b}$ appears in the as-polished condition at higher magnification in figure 23.

In the sections examined, only one of the welded seams exhibited an opening or incipient opening --- the pipe sample from 8 Clayton $\mathrm{Ct}$. The welded seam had begun to crack at the inside of the pipe. An etched cross section showing the crack appears in figure 24. The crack path appears to be transgranular. This same weld exhibited a small imperfection at the outside of the pipe. This imperfection does 
not look like a crack and it does not appear to be of any significance. There was a considerable amount of cross sectional deformation in the pipe where the crack had formed (figure 12d). Because of the location of the weld with respect to the deformation, the transverse tensile stress on the inside of the pipe at the weld would have been increased by the deformation.

As expected, all of the sections examined exhibited corrosion product in varying amounts on the outside pipe surface. The sample designated 10 had one of the heaviest layers of corrosion product (figure 25).

Of those examined, the cross section of the sample from $31 \mathrm{~s}$. Bennywell was the only one to exhibit a significant amount of corrosion product on the inside (figure 26 ).

The microstructure of all the sections examined consisted primarily of ferrite with a small amount of pearlite. There were differences in grain size and texture as can be seen in figures 27 and 28 which show different cross sections at the same magnification. There were only minor differences in microstructure at the welded seams as can be seen in figures 24 and 29. In these two figures, the relationship between the parent material and the weld is typical of those sections examined.

Some of the cross sections examined exhibited evidence of decarburization adjacent to the inside and original outside pipe surfaces. An example is shown in figure 30 .

\subsubsection{Hardness Measurements}

Rockwell B (HRB) hardness measurements were made on the cross sections through each pipe sample where the original wall thickness measurements were made. The results of these measurements are given in Table 2. Each of the average values presented is based on three measurements. There was considerable variation in hardness among the different pipe samples. None of these measurements was taken at a bend in the pipe; therefore, differences in hardness can not be attributed to strain.hardening of the material due to the bending operation. In all cases, the hardness at the weld was lower than or equal to the hardness elsewhere in the cross section for a given sample.

\section{DISCUSSION}

\subsection{Pipe Sample From 13 Clayton Court}

The pipe sample from 13 Clayton Court was very severely corroded. There were several perforations in the most severely corroded region which was located at the bend. No significant corrosion was observed on the inside of the pipe. 
There was some slight mechanical damage, although not near the perforations. This damage appeared to have occurred a short time before the pipe was submitted to NBS. It should have had little adverse effect on the integrity of the pipe.

The original wall thickness of the pipe would satisfy the current requirements of appropriate ASTM Standards.

The microstructure, consisting of ferrite and some pearlite, appeared to be satisfactory. The microstructure of the weld appeared to be compatible with that of the parent material. The hardness of the weld and parent material also appeared to be compatible.

The weld appeared to be sound. There was no evidence to indicate that the weld was opening. Cross sectional deformation which could have increased the stress in the weld was negligible.

\subsection{Pipe Samples Other Than That From 13 Clayton Court}

All of the pipe samples had suffered corrosion to some extent. The degree of corrosive attack varied considerably among the various samples. Some samples such as those from 1 Clayton Ct. and 7 Clayton Ct. were corroded only mildly, whereas others had been much more severely corroded. The sample identified as 7 had been perforated in one place. No significant corrosion was observed on the inside of any of the pipe samples except for the one from $31 \mathrm{~S}$. Bennywel1.

The sleeves that covered the pipe where it passed through a wall or floor appeared to have no deleterious effect on the condition of the pipe itself. Actually, the pipe appeared to be less severely corroded where it had been covered than where there had been no sleeve.

The average wall thickness measured in the least corroded regions would satisfy the current ASTM requirements for the original wall thickness for all of the pipe samples. In severely corroded regions, the minimum wall thickness of only two samples satisfied the current minimum wall thickness requirements.

The only observed instance of significant mechanical damage that may have influenced the deterioration of any of the samples was in the pipe identified as 7. This pipe sample appeared to have been "pushed in" around the perforation. It is not clear when this damage occurred, but there was corrosion product over the entire "pushed in" area much like that is surrounding areas. There was no shiny metal in evidence to indicate that the pipe had been recently struck in this area.

Removal of rust from the surface of some of the pipe samples revealed no significant change in the apparent condition of the samples. 
Except for the one sample that had been perforated (sample 7), all of the samples satisfactorily withstood a leak test at a pressure of. 30 psig natural gas.

All the welds appeared to be in satisfactory condition except for the one in the sample from 8 clayton $C t$. This weld was cracked on the inside of the pipe at the bend where there was a considerable amount of cross sectional deformation. For the cross sections examined, the microstructure of the weld was very similar to that of the parent material for any given sample. For all of the samples, the hardness of the weld material was either less than or the same as that of the parent material. The hardness of the weld and parent materials appeared to be compatible.

Cross sectional deformation was observed in the bends of a number of the samples. This deformation evidently occurred when the bends were made. None of the cross sections examined exhibited an excessive inclusion content. There was a significant "line" of porosity in the sample from $31 \mathrm{~S}$. Bennywe11. The microstructures of all the samples examined consisted of ferrite and some pearlite, but there were some differences in grain size and texture. There was some apparent decarburization in varying degrees adjacent to both the inside and outside wall surfaces. This decarburization should have had no significant effect on the pipe.

Since all of the pipes tested withstood the leak tests, they should have been performing satisfactorily in service. Several of the samples had deteriorated seriously, however, and if they had been left in service and the corroding conditions had persisted, in time others may have perforated in the same manner as sample 7. Even before perforation occurs, the load bearing ability of the material is decreased by the thinning of the walls by corrosion. The decrease in load bearing ability increases the susceptibility of the pipes to fracture from an externally applied force.

\subsection{General Discussion}

It was reported, as indicated in the section on background information, that the crawl spaces where these pipes were located were poorly ventilated. Therefore, a rather high concentration of water vapor would be expected to be present. A suggested source of the corroding medium is water vapor that condensed on the vertical part of the pipe and ran down to the bend or to the more nearly horizontal part of the pipe where it would concentrate.

\section{CONCLUSIONS}

\subsection{Pipe Sample From 13 clayton Court}

1. The sample from 13 Clayton Court was severely corroded over the entire length submitted. Corrosion was severe enough in one region to result in perforation of the pipe wall. 
2. Corrosion of the inside wall of the pipe was negligible except for one sample.

3. No mechanical damage that might have contributed to the failure was observed.

4. Cross sectional deformation at the bend was negligible.

5. The initial wall thickness of the pipe would have met current specifications.

6. The weld exhibited no evidence of opening.

7. The microstructure and hardness of the weld appeared to be compatible with those of the parent material.

\subsection{Pipe Samples Other Than That From 13 Clayton Court}

1. All of the pipe samples were corroded, but the degree of corrosion among the various samples varied from mild to severe. One of the samples had corroded severely enough that it had been perforated.

2. Corrosion of the inside of the pipes was negligible.

3. There was significant mechanical damage in one sample at a perforation.

4. Except for the sample that was perforated, all the samples withstood a leak test at 30 psig natural gas.

5. Removal of the rust from the pipe surfaces did not reveal any significant change in the condition of any of the samples.

6. There was a considerable amount of cross sectional deformation at the bend in several of the samples.

7. The initial wall thickness of all the pipe samples would have met current specifications.

8. The minimum wall thicknesses in regions of severe corrosion were less than that currently specified except for two samples.

9. The weld in the sample from 8 clayton $\mathrm{Ct}$. had cracked on the inside of the pipe.

10. All of the welds except for the one in the sample from 8 clayton Ct. appeared to be in satisfactory condition.

11. The microstructure and hardness of the welds appeared to be compatible with those of the parent material. 
12. There was a significant amount of porosity in the sample from 31 S. Bennywe11.

\section{ACKNOWLEDGEMENT}

The wall thickness measurements, hardness tests, metallographic specimen preparation and photographic work were performed by L. C. Smith of the NBS Mechanical Properties Section. Mr. Smith also assisted in the leak testing.

\section{REFERENCE}

1. Standard A53-73 or Standard A120-73, 1976 Book of Standards, American Society for Testing and Materials, Philadelphia, Pennsylvania, 1976. 
Table 1. Results of Wall Thickness Measurements

Pipe Sample

Wall Thickness, inches

\begin{tabular}{ll} 
In Least Corroded Region & $\begin{array}{l}\text { In Most Severely } \\
\text { Corroded Region }\end{array}$ \\
\hline
\end{tabular}
Average Range Minimum

13 Clayton Court

0.155

$0.152-0.156$

$0.000 *$

1 Clayton Ct.

0.154

$0.153-0.155$

0.140

2 Clayton Ct.

0.153

$0.150-0.157$

0.080

5 Clayton Ct.

0.155

$0.154-0.156$

0.141

6 Clayton Ct.

0.154

$0.148-0.155$

0.023

7 Clayton Ct.

0.152

$0.150-0.155$

0.129

8 Clayton Ct.

0.156

$0.154-0.158$

0.079

9 Clayton Court

0.155

$0.154-0.158$

0.121

12 Clayton Ct.

0.158

$0.155-0.160$

0.122

31 S. Bennywe11(?)

0.141

$0.140-0.145$

0.035

7

0.152

$0.148-0.153$

$0.000 *$

10

0.152

0.150-0.154

0.022

13 s. Cannon Dr.

0.151

0.150-0.152

0.067

18 S. Cannon

0.154

0.152-0.155

0.068 
Table 2. Results of Hardness Measurements

Pipe Sample Rockwel1 B Hardness (HRB)

In weld

Average away from weld

13 Clayton Court

63

69

1 Clayton Ct.

55

64

2 Clayton $\mathrm{Ct}$.

58

66

5 Clayton Ct.

60

72

6 Clayton Ct.

67

74

7 Clayton Ct.

59

65

8 Clayton Ct.

67

70

9 Clayton Court

70

74

12 Clayton Ct.

59

70

31 S. Bennywe11(?)

52

65

7

58

61

10

50

53

13 S. Cannon Dr.

59

61

18 s. Cannon

59

59

Table 3. Cross Sectional Deformation at the Bend in the Pipe Pipe Sample Inside Diameter, inches Maximum Minimum

Difference

1 Clayton Ct.

0.82

0.58

0.24

5 Clayton Ct.

.81

.60

.21

7 Clayton Ct.

.86

.54

.32

8 Clayton Ct.

.84

.53

.31

9 Clayton Court

.78

.64

.14 



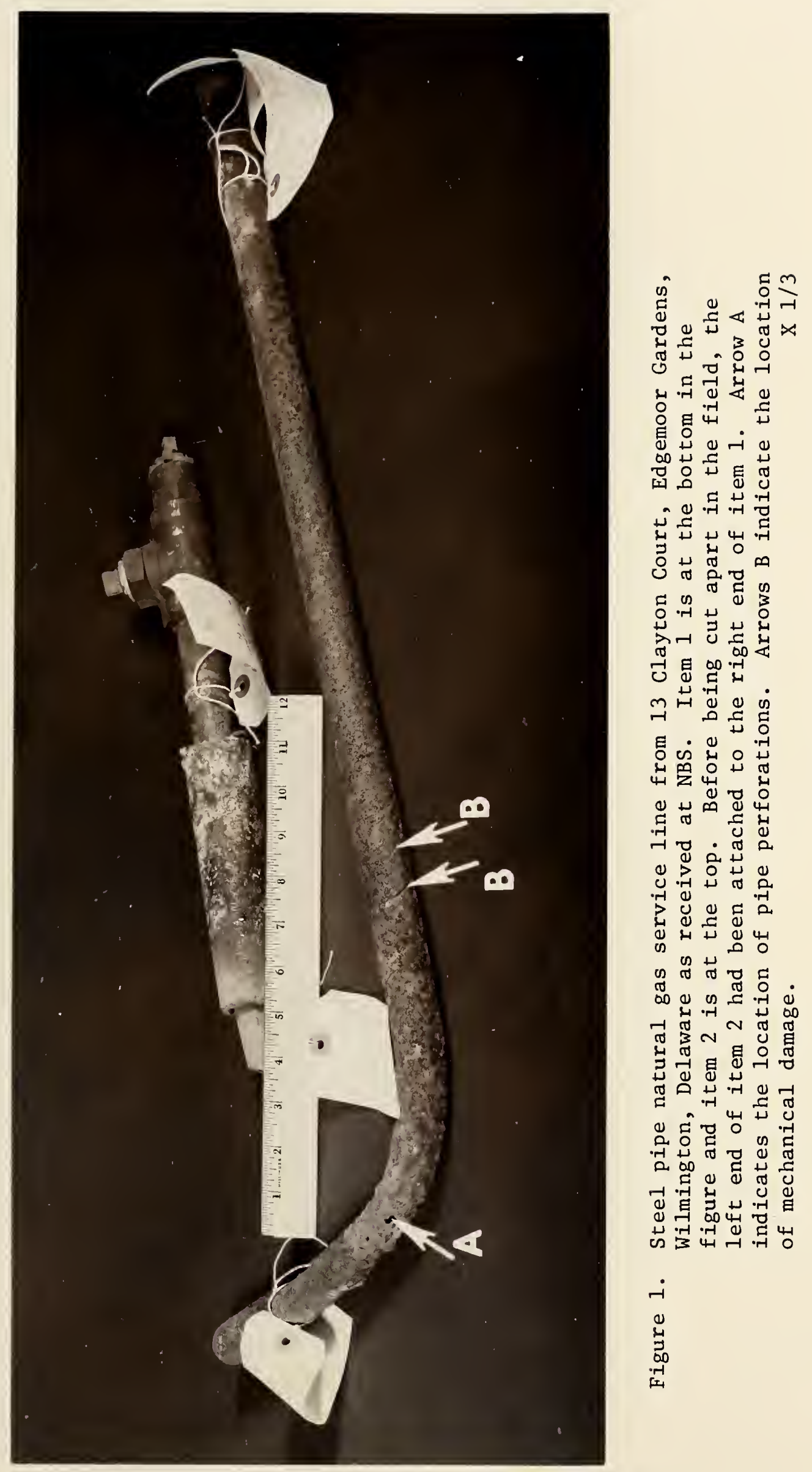





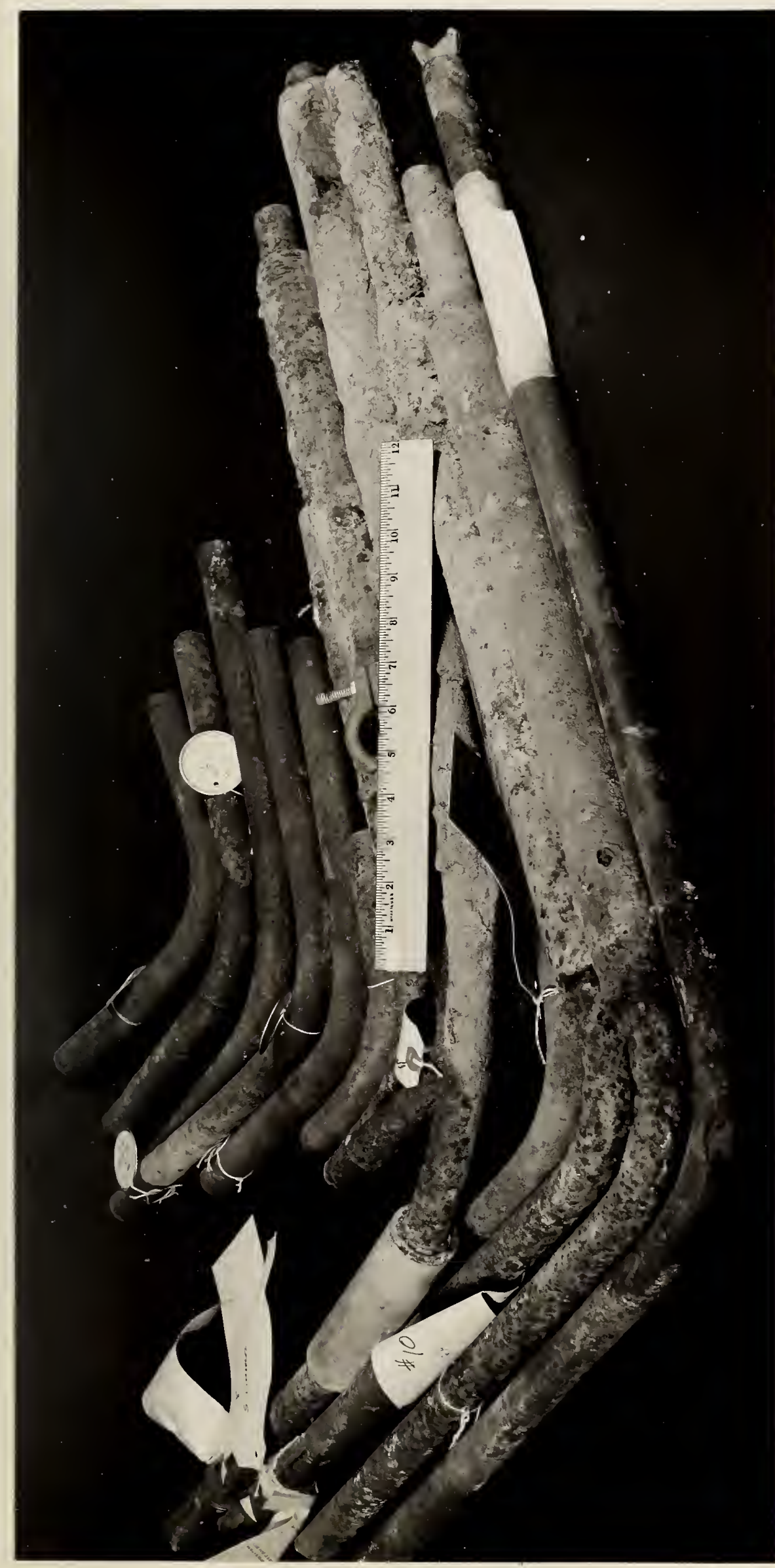

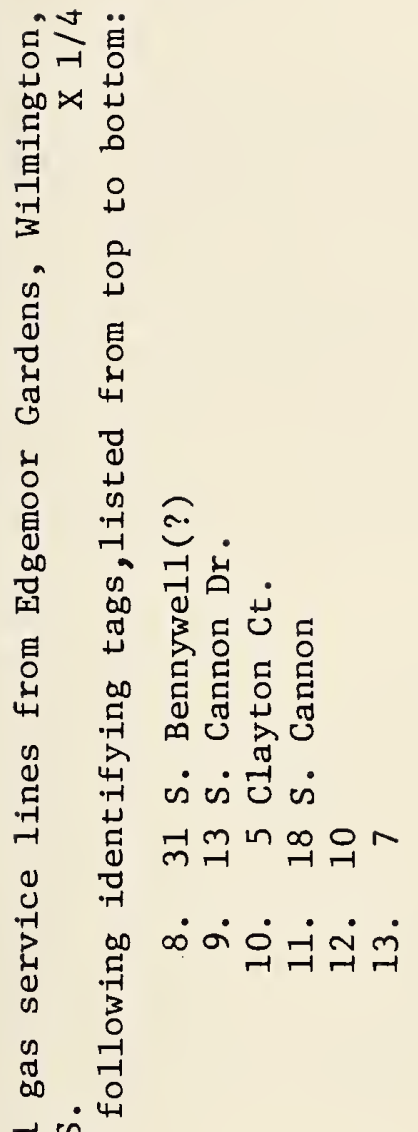

नic is

运

茫

娄

그

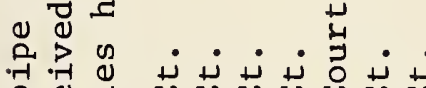

○ ه

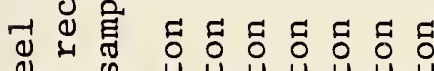

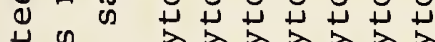

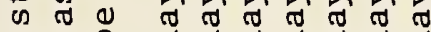

द ब. न्न

व $\wedge \omega n a \infty N$

430

荧营 क

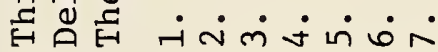

$\dot{\sim}$

虫 


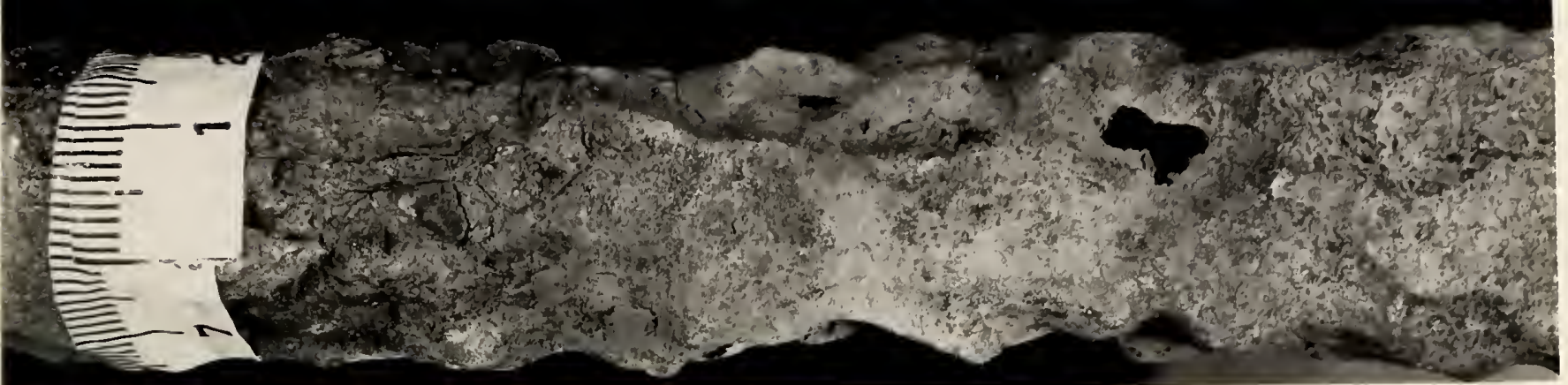

a

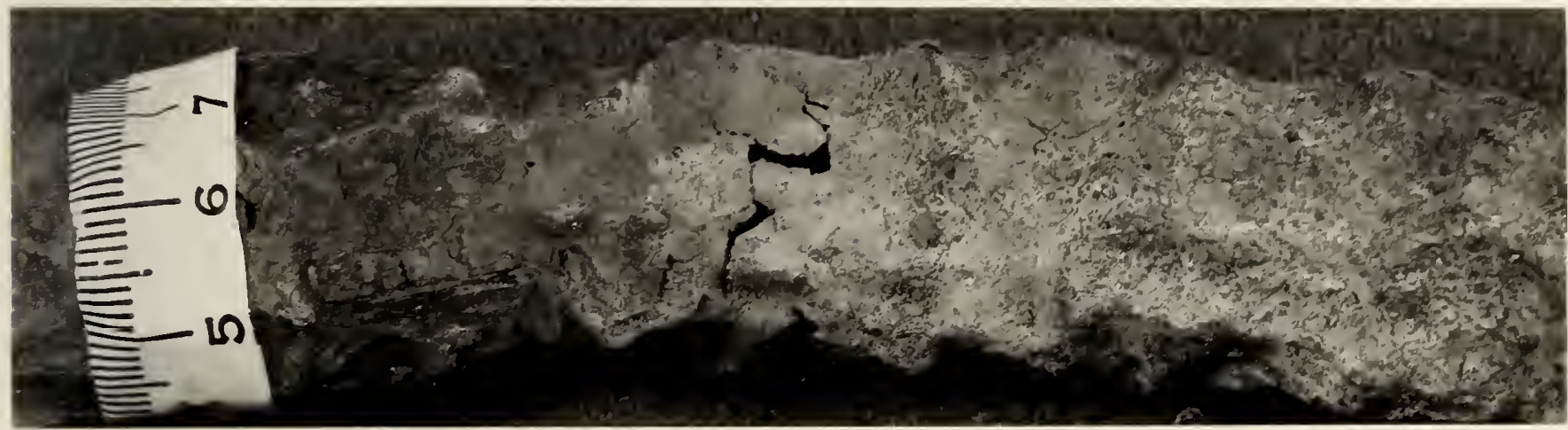

b

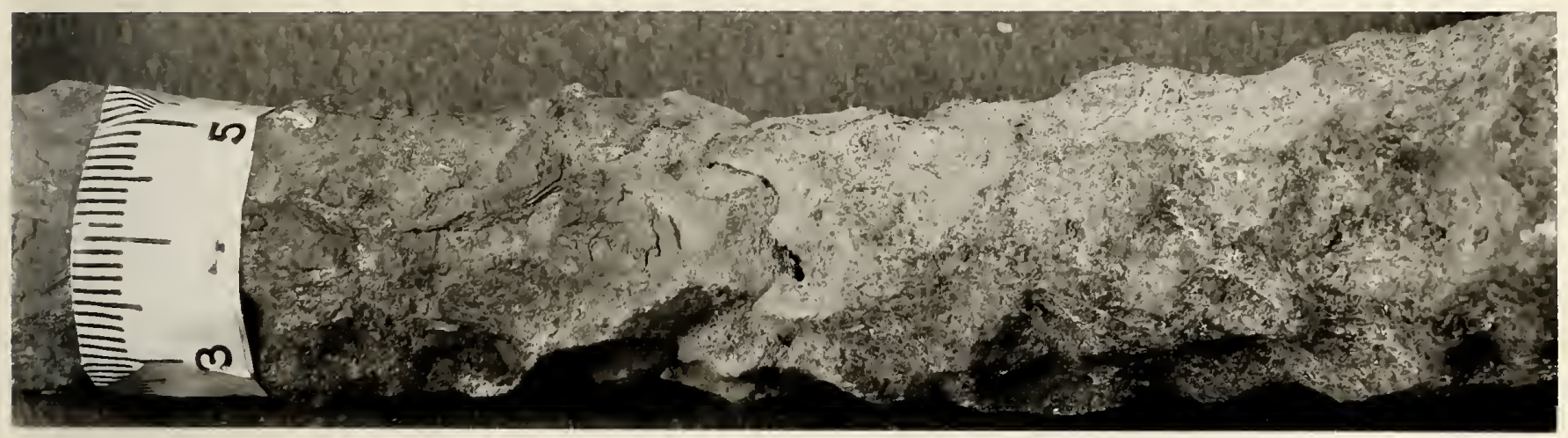

C

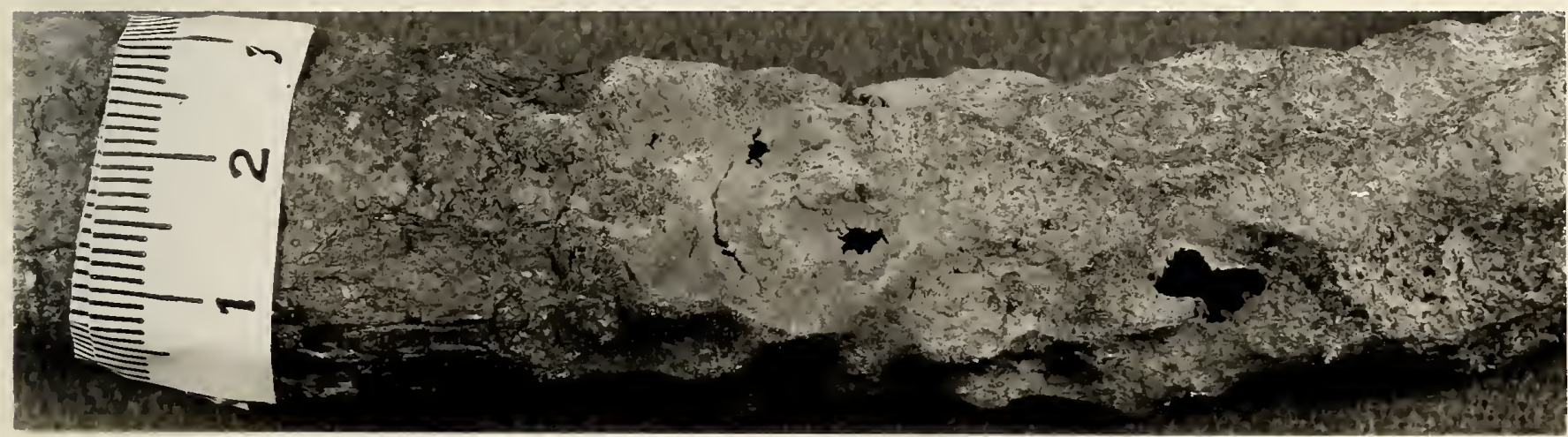

d

Figure 3. Four views around the circumference of the pipe from 13 Clayton Court showing extensive corrosion. These views are approximately at the location of arrow $A$ in figure 1. $\mathrm{X} \perp 1 / 2$ 
- 


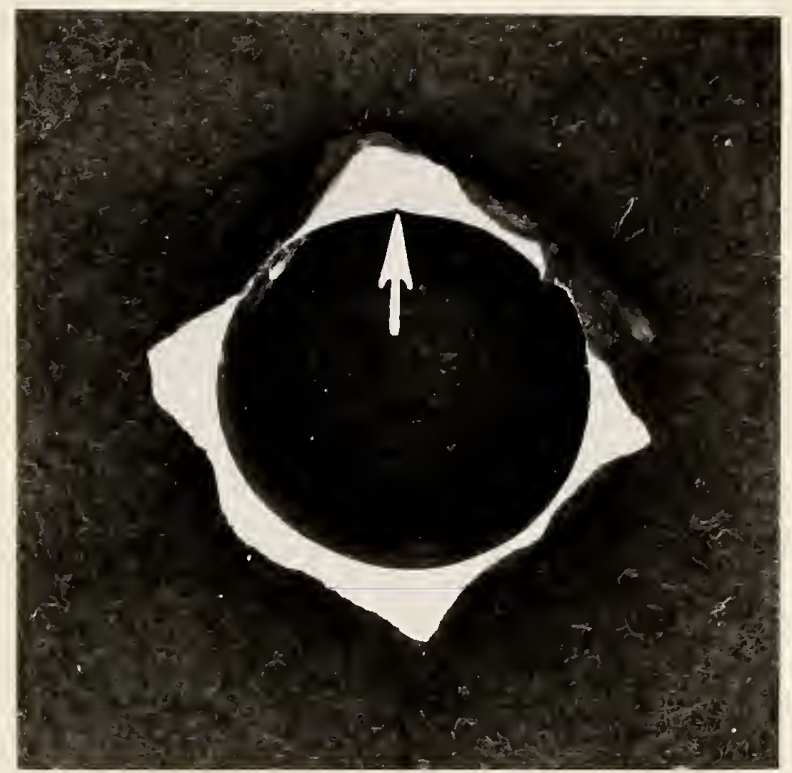

Figure 4. Cross section through severely corroded region of pipe from 13 Clayton Court. The welded seam is indicated by the arrow.

X 2

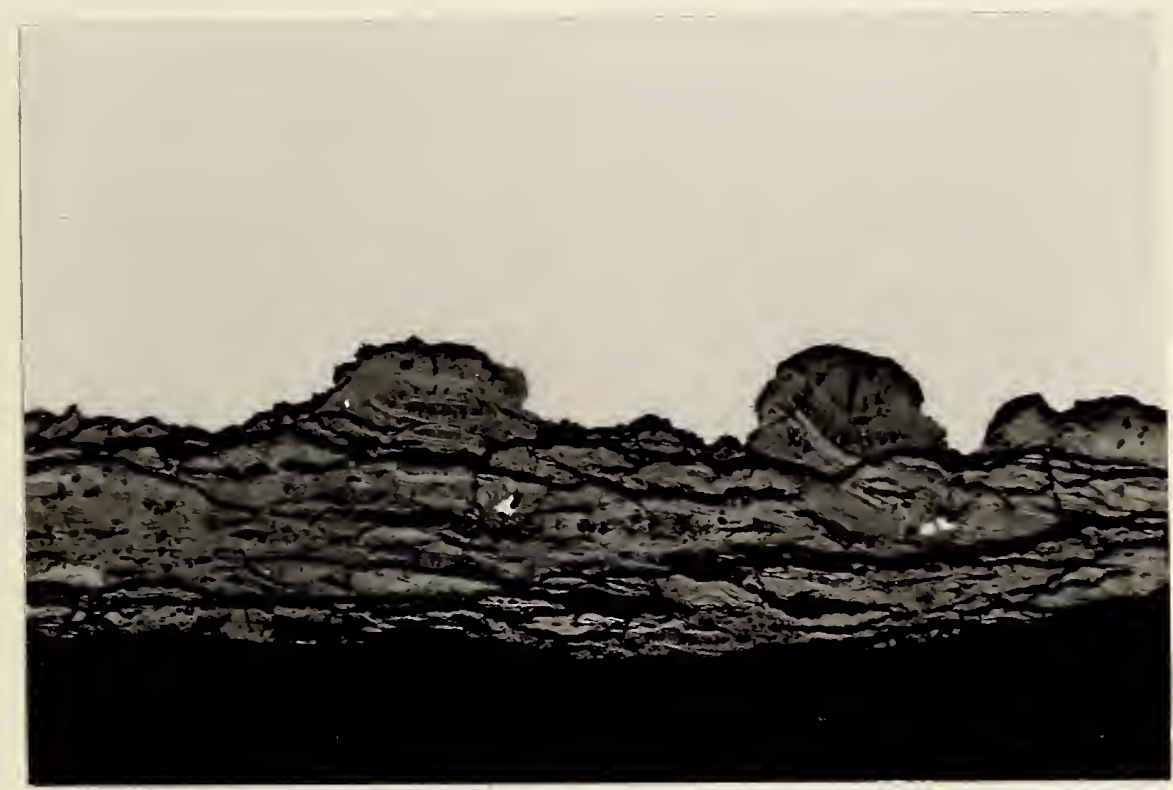

Figure 5. Unetched cross section through pipe from 13 Clayton Court. Light region is pipe material. Light gray region adjacent to the pipe material is corrosion product. As polished. 



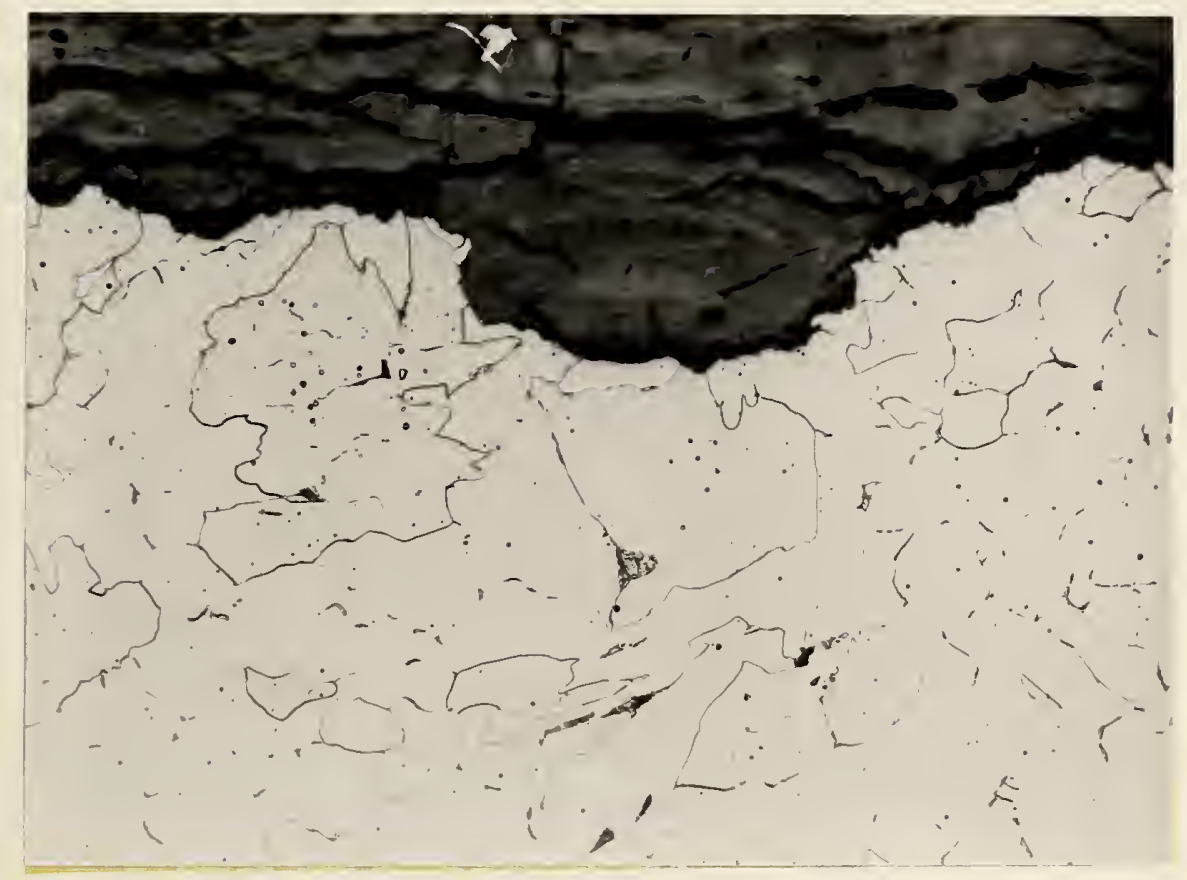

Figure 6. Etched cross section through pipe from 13 clayton Court. Dark gray material at the top is corrosion product. Microstructure consists primarily of ferrite with some pearlite.

Etchant: $1 \%$ nital X 200 



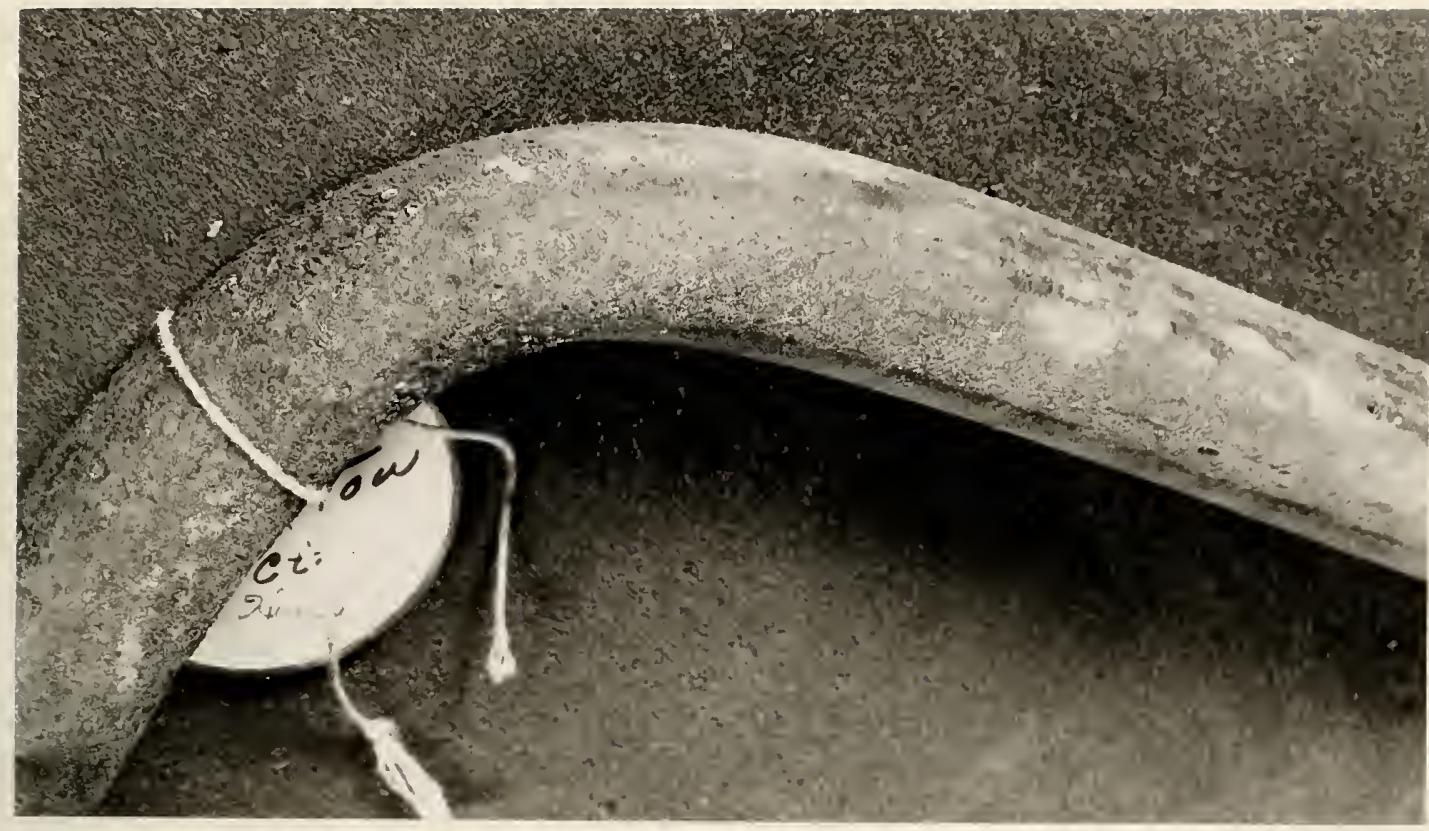

a

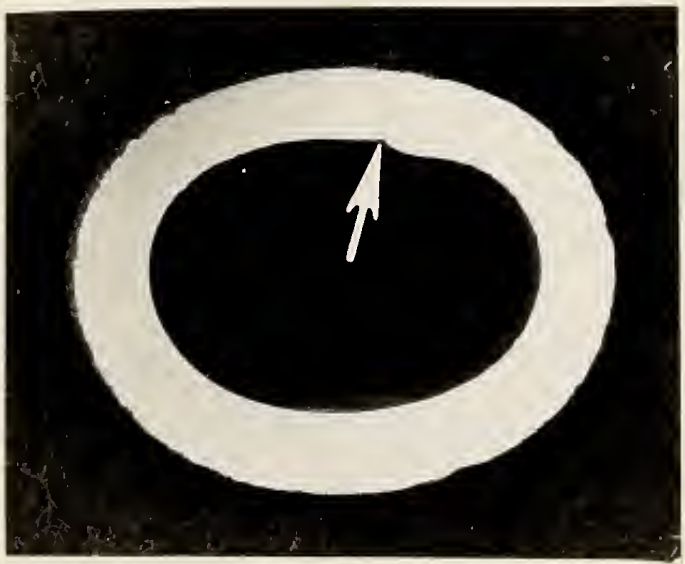

b

Figure 7. Pipe from 1 Clayton Ct.

a. Bend region of pipe as received at NBS showing corrosion.

X 1

b. Cross section through bend showing cross sectional deformation. The welded seam is indicated by the arrow. 



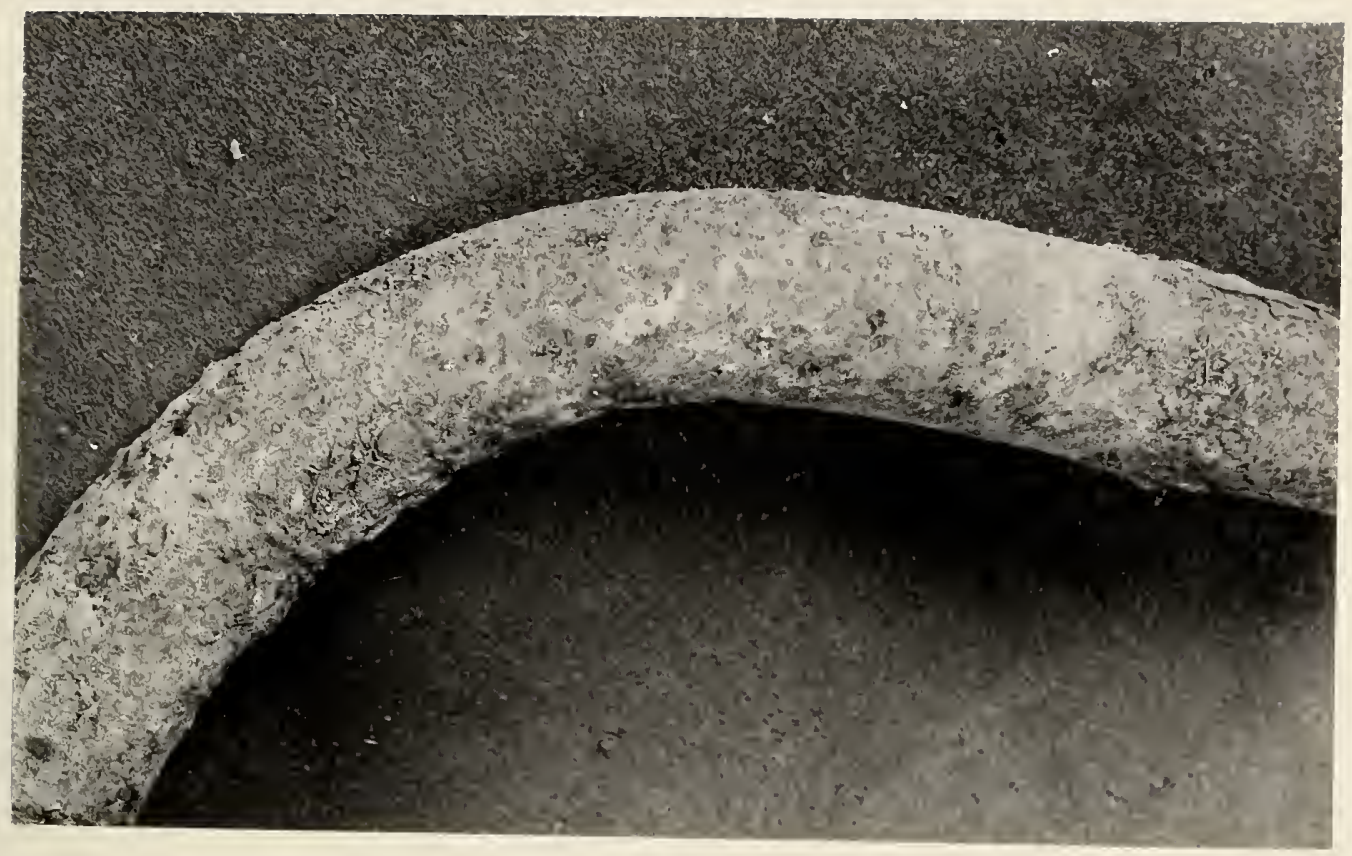

a

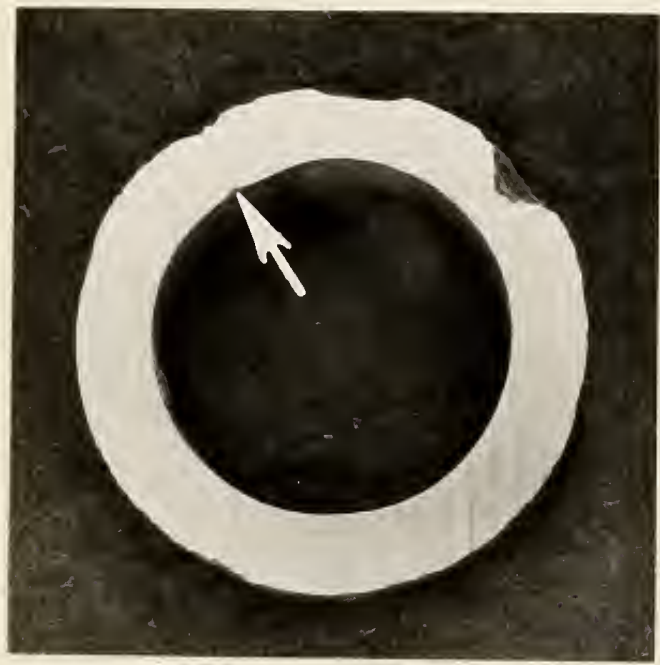

b

Figure 8. Pipe from 2 Clayton $\mathrm{Ct}$.

a. Bend region of pipe as received at NBS showing corrosion. $\mathrm{X} 1$

b. Cross section through a corroded region not at the bend in the pipe. The welded seam is indicated by the arrow. $\quad \mathrm{X} 2$ 



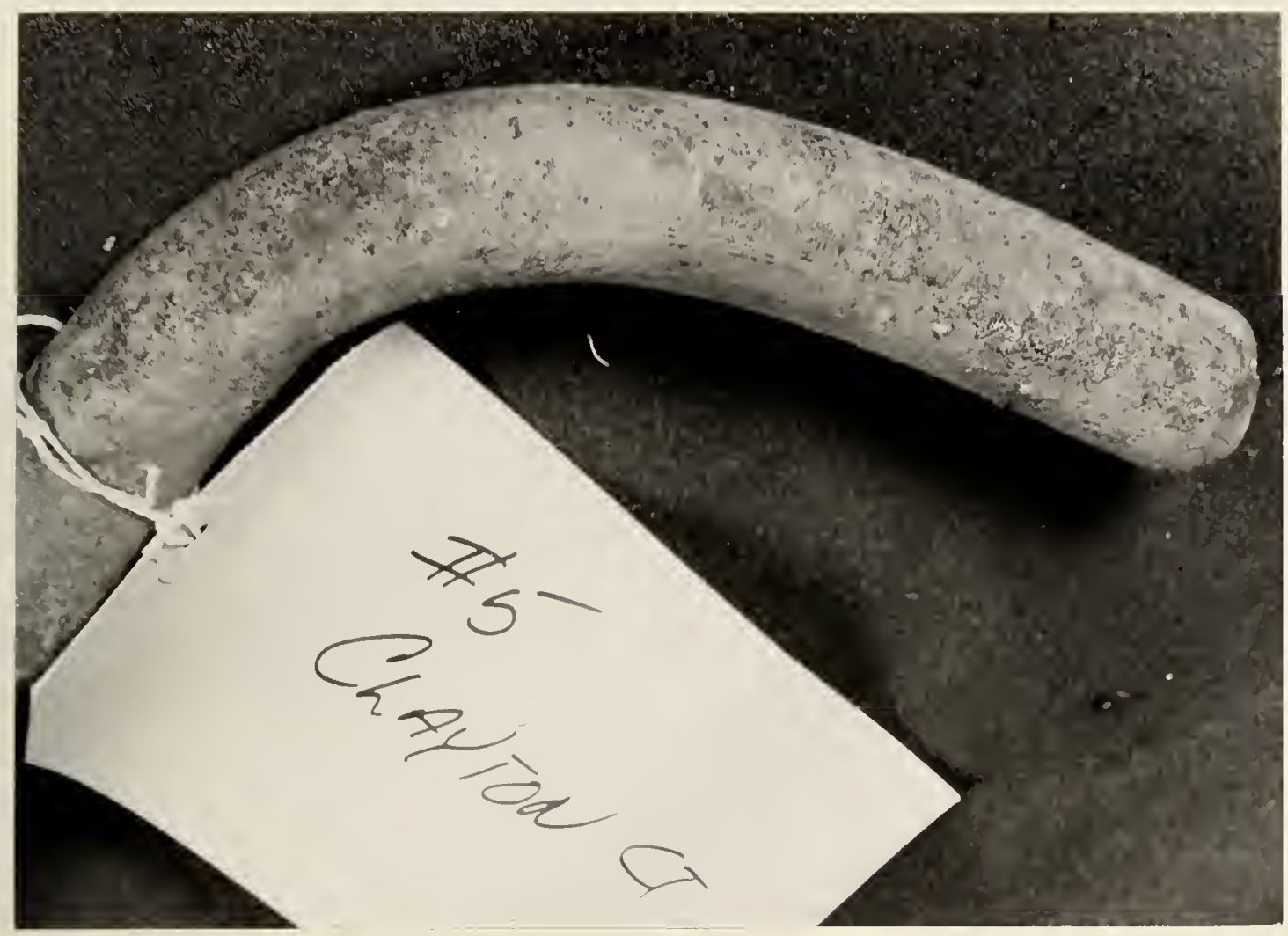

a

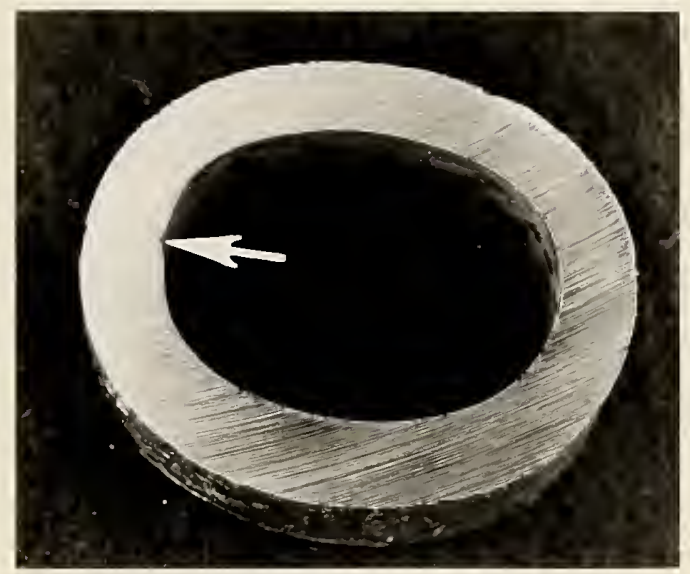

b

Figure 9. Pipe from 5 Clayton Ct.

a. Bend region of pipe as received at NBS showing corrosion.

X 1

b. Cross section through bend showing cross sectional deformation. The welded seam is indicated by the arrow. 



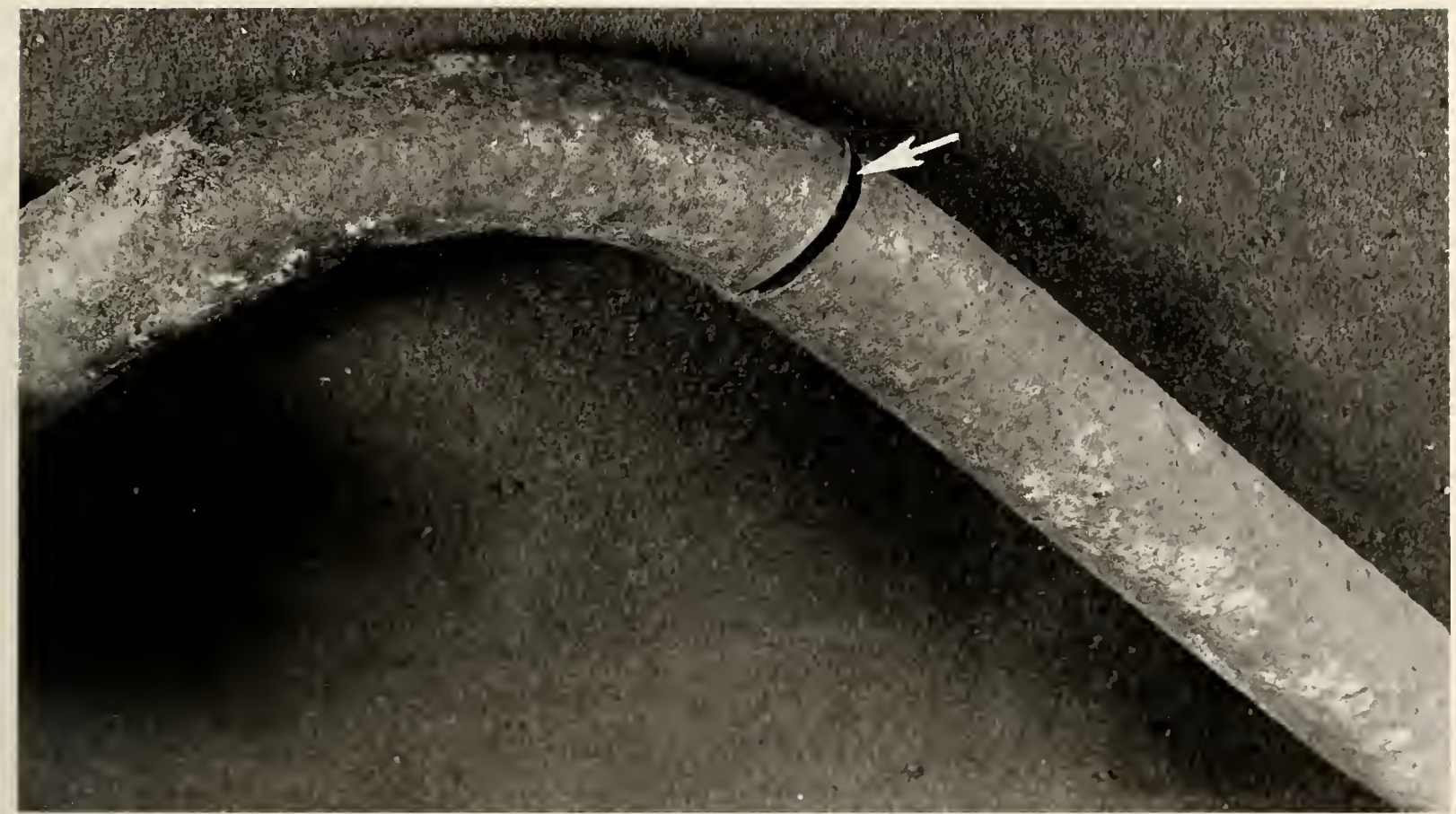

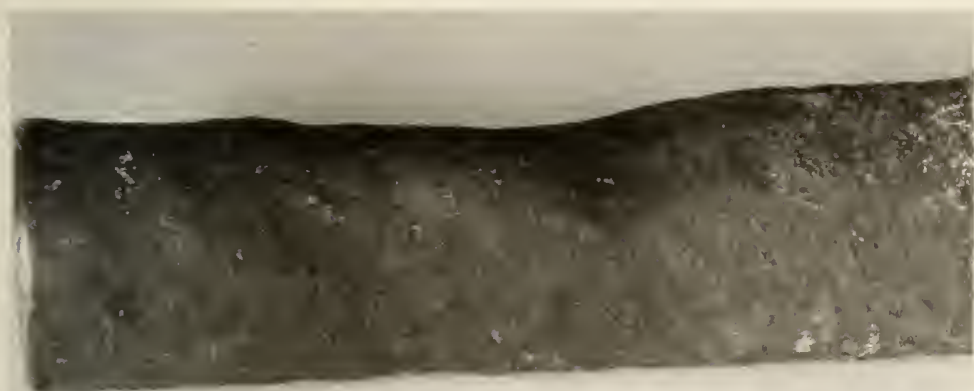

$\mathrm{b}$

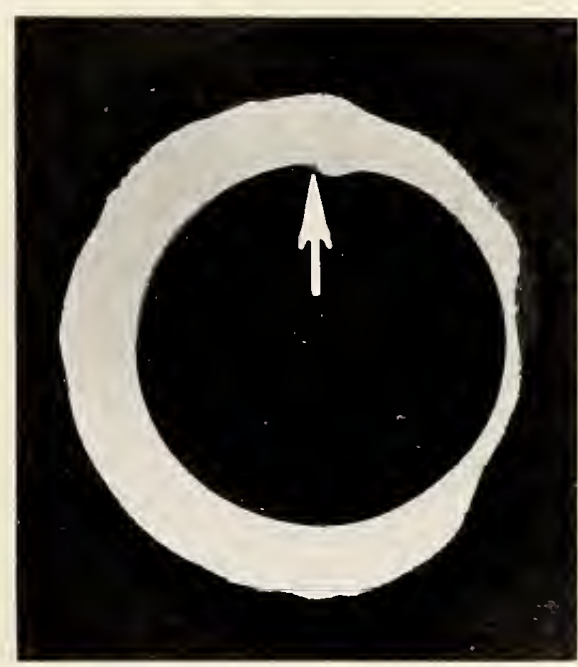

c

Figure 10. Pipe from 6 Clayton $\mathrm{Ct}$.

a. Bend region of pipe as received at NBS showing corrosion. Arrow indicates partial cut apparently made by a pipe cutting tool.

b. Region of severe corrosion about 8 inches from the bend. $X 1$

c. Cross section through region shown in figure $10 \mathrm{~b}$. The welded seam is indicated by the arrow. 



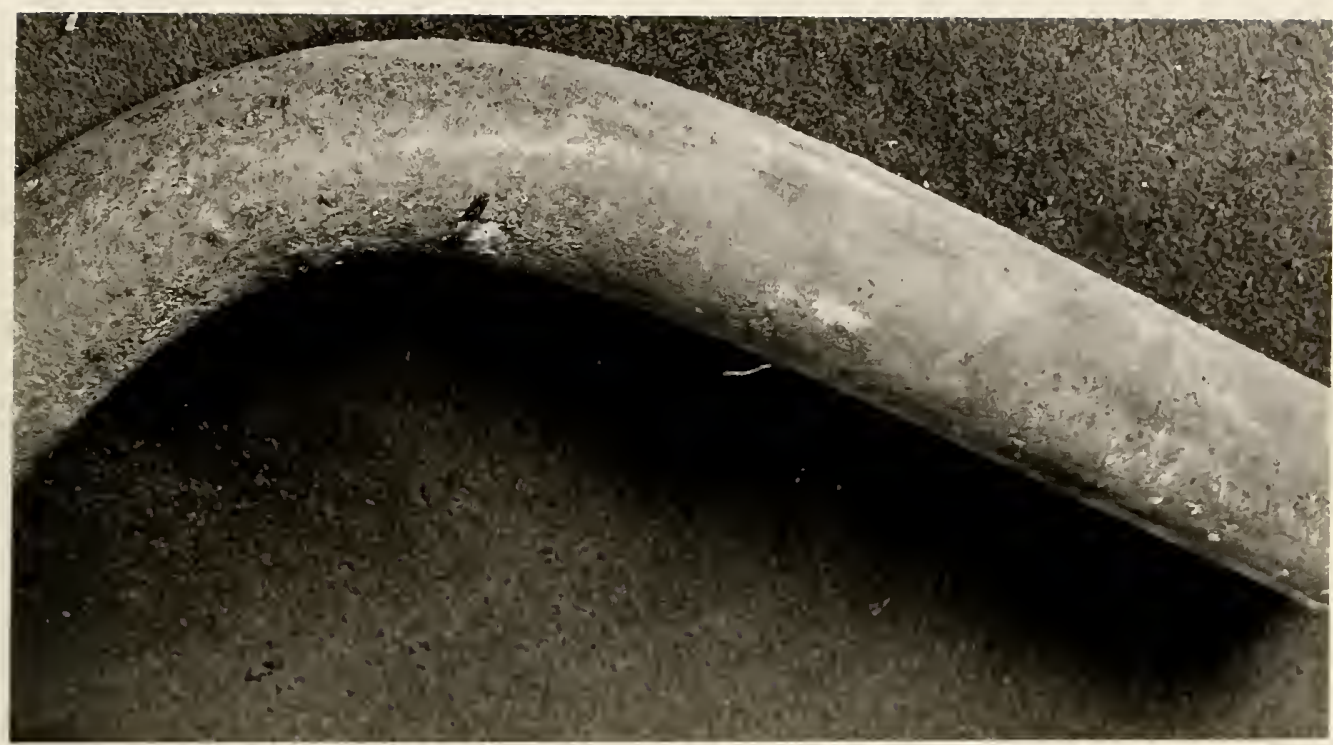

a

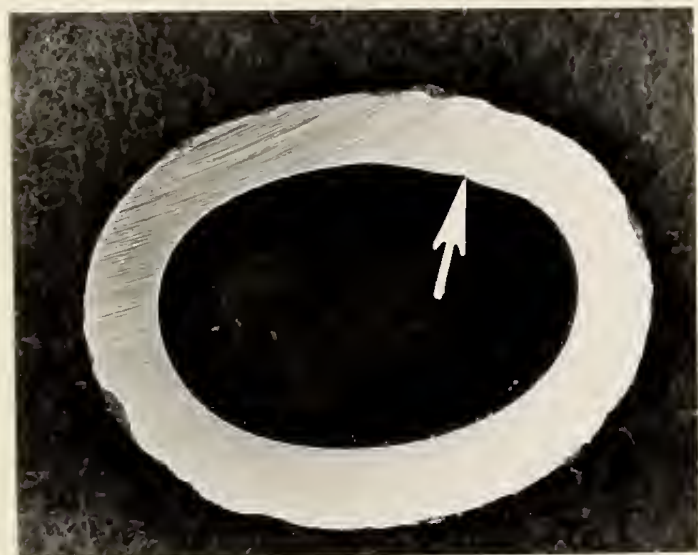

b

Figure 11. Pipe from 7 Clayton Ct.

a. Bend region of pipe as received at NBS showing corrosion.

$\mathrm{X} 1$

b. Cross section through bend showing cross sectional deformation. The welded seam is indicated by the arrow. 



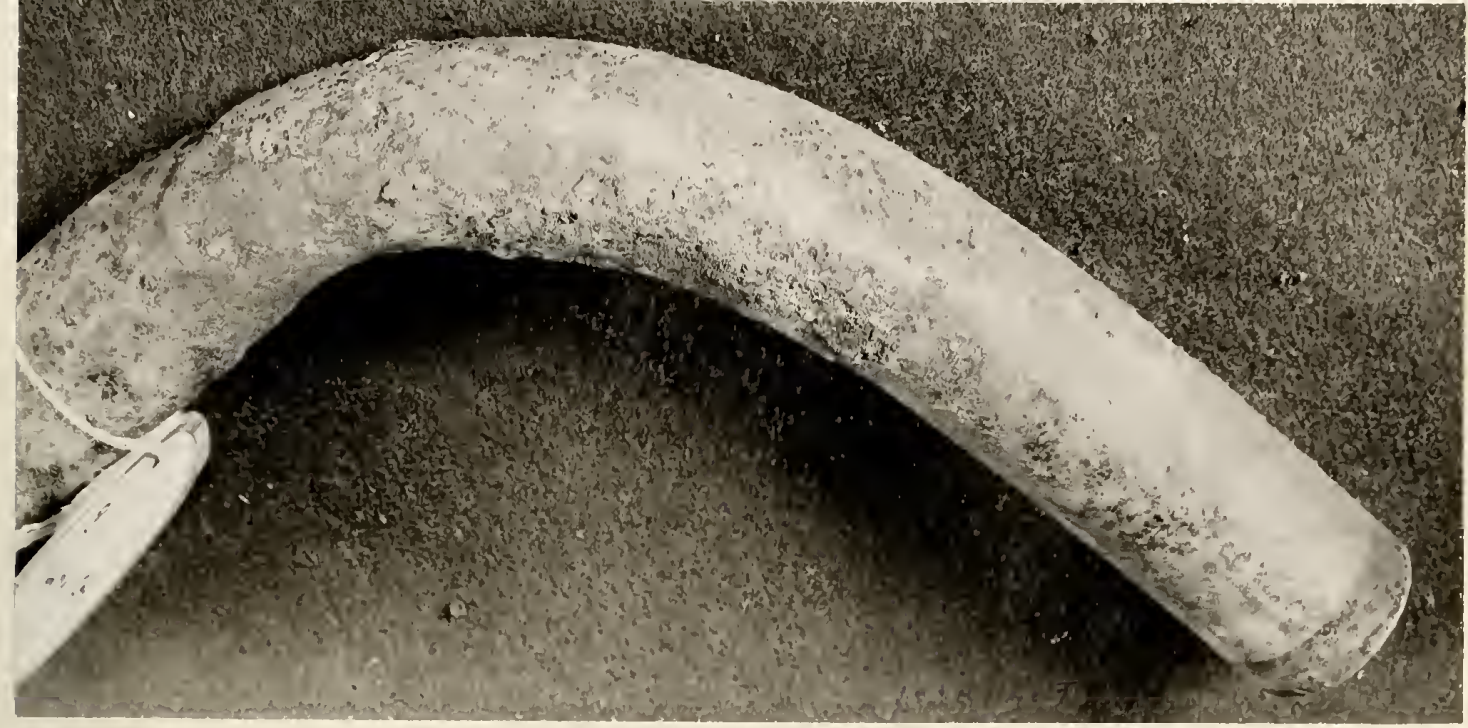

a

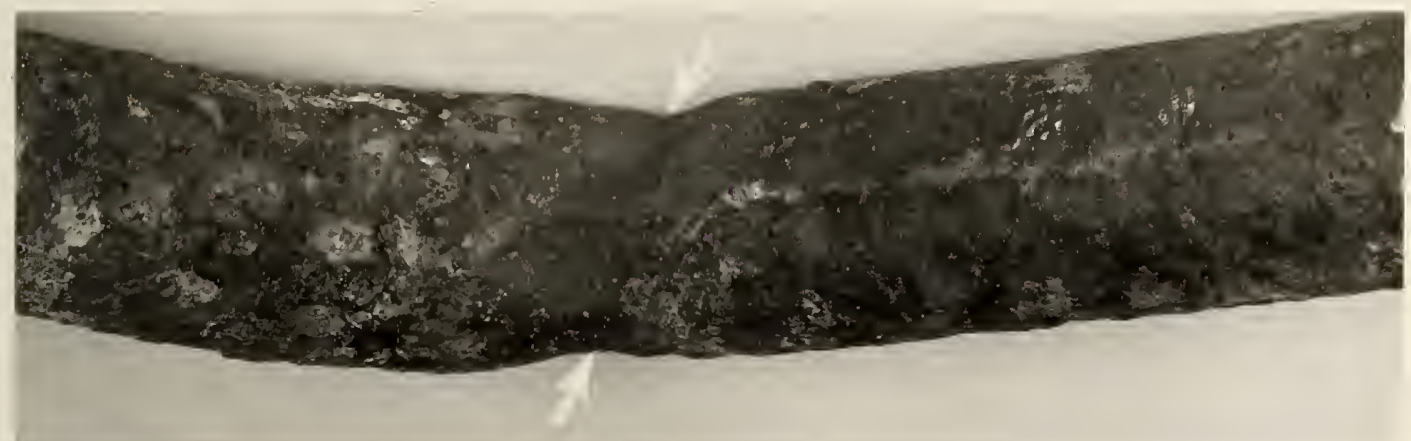

b

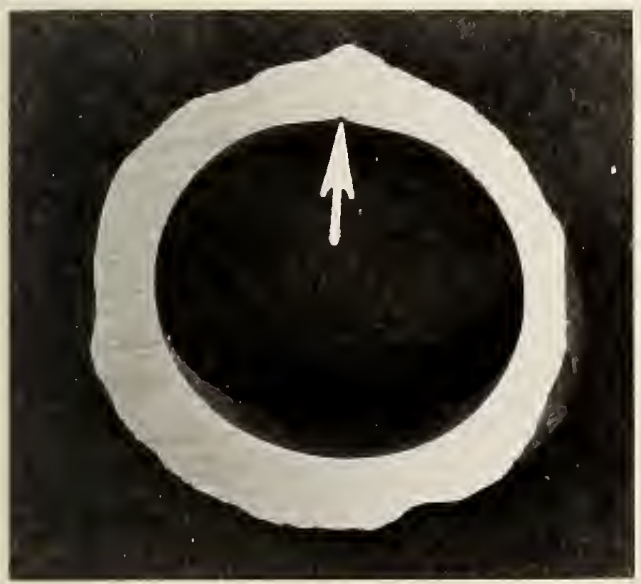

c

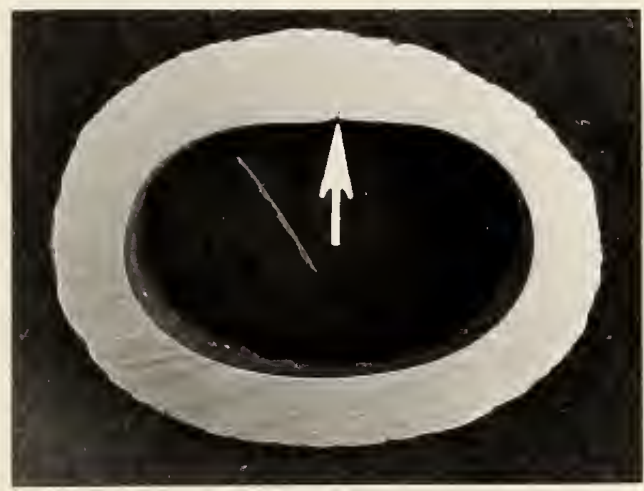

d

Figure 12. Pipe from 8 Clayton $\mathrm{Ct}$.

a. Bend region of pipe as received at NBS showing corrosion.

$\mathrm{X} 1$

b. Region of severe corrosion at end of bend (arrows). $\times 1$

c. Cross section through pipe in region of severe corrosion shown in figure $12 \mathrm{~b}$. The welded seam is indicated by the arrow. $\mathrm{X} 2$

d. Cross section through bend showing cross sectional deformation. The welded seam is indicated by the arrow. $\mathrm{X} 2$ 



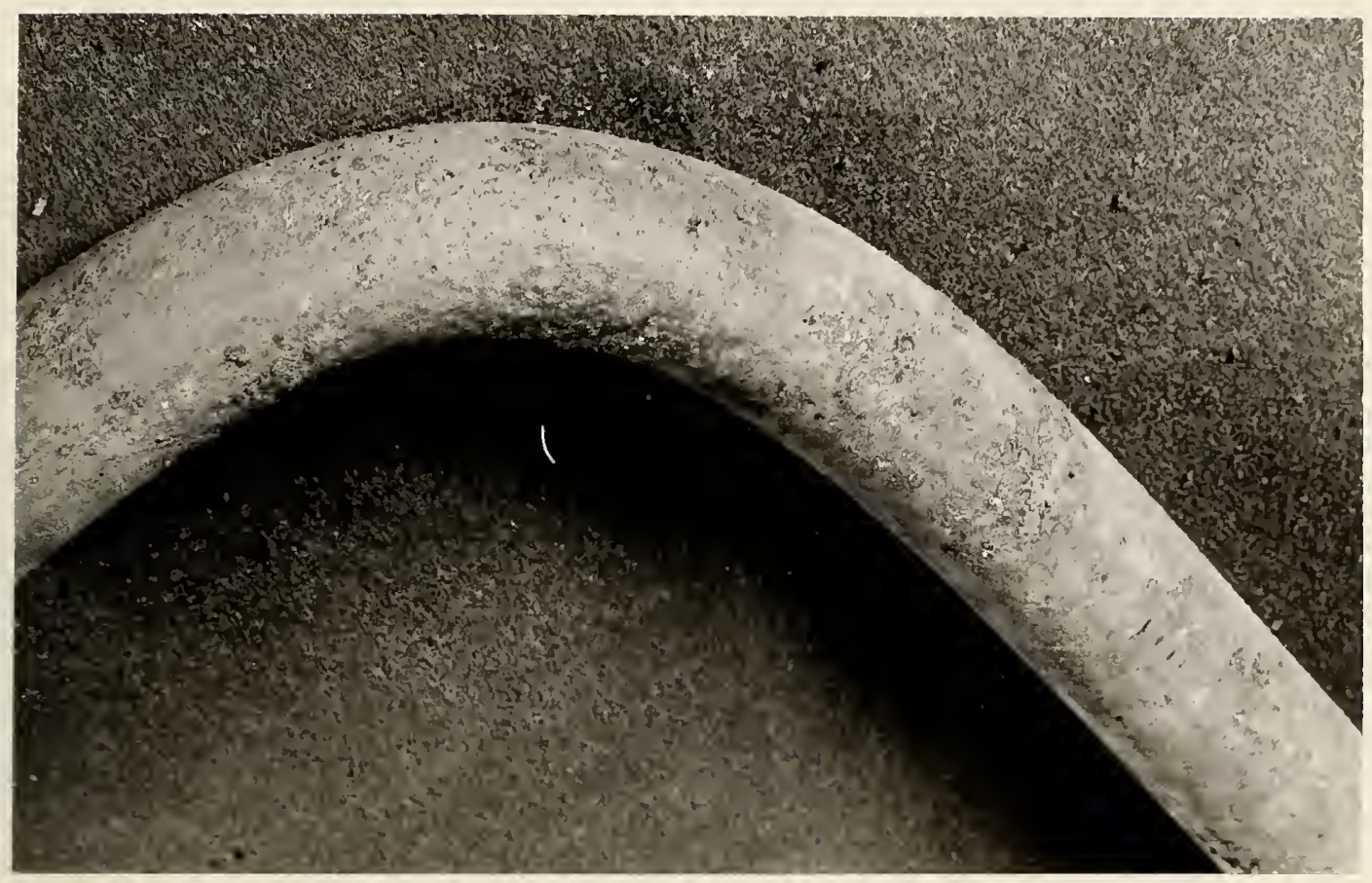

a

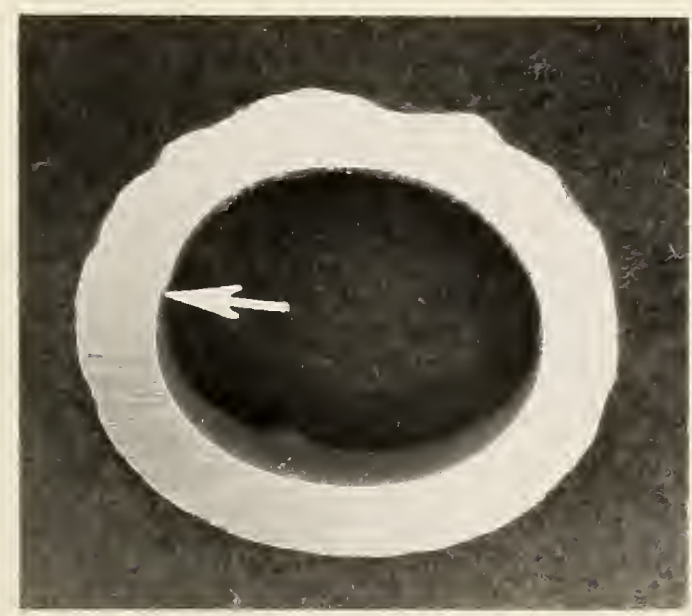

b

Figure 13. Pipe from 9 Clayton Court.

a. Bend region of pipe as received at NBS showing corrosion. $\mathrm{X} 1$

b. Cross section through bend showing cross sectional deformation. The welded seam is indicated by the arrow. 


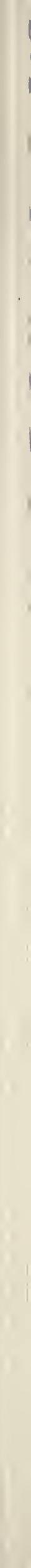




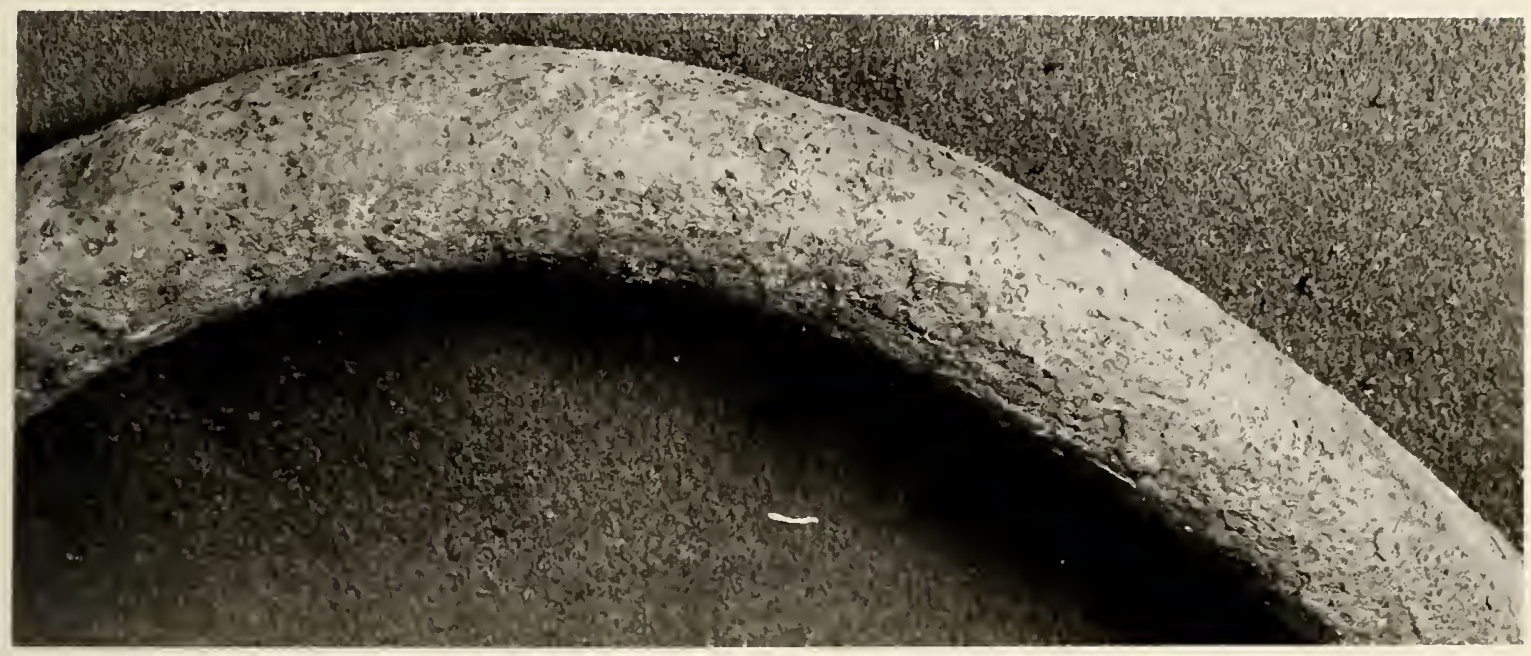

a

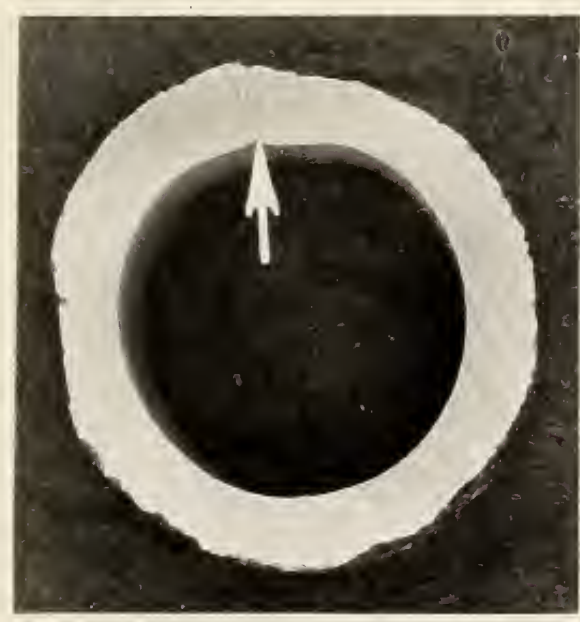

b

Figure 14. Pipe from 12 Clayton Ct.

a. Bend region of pipe as received at NBS showing corrosion.

$\mathrm{X} 1$

b. Cross section through bend showing essentially no cross sectional deformation. The welded seam is indicated by the arrow. $\mathrm{X} 2$ 



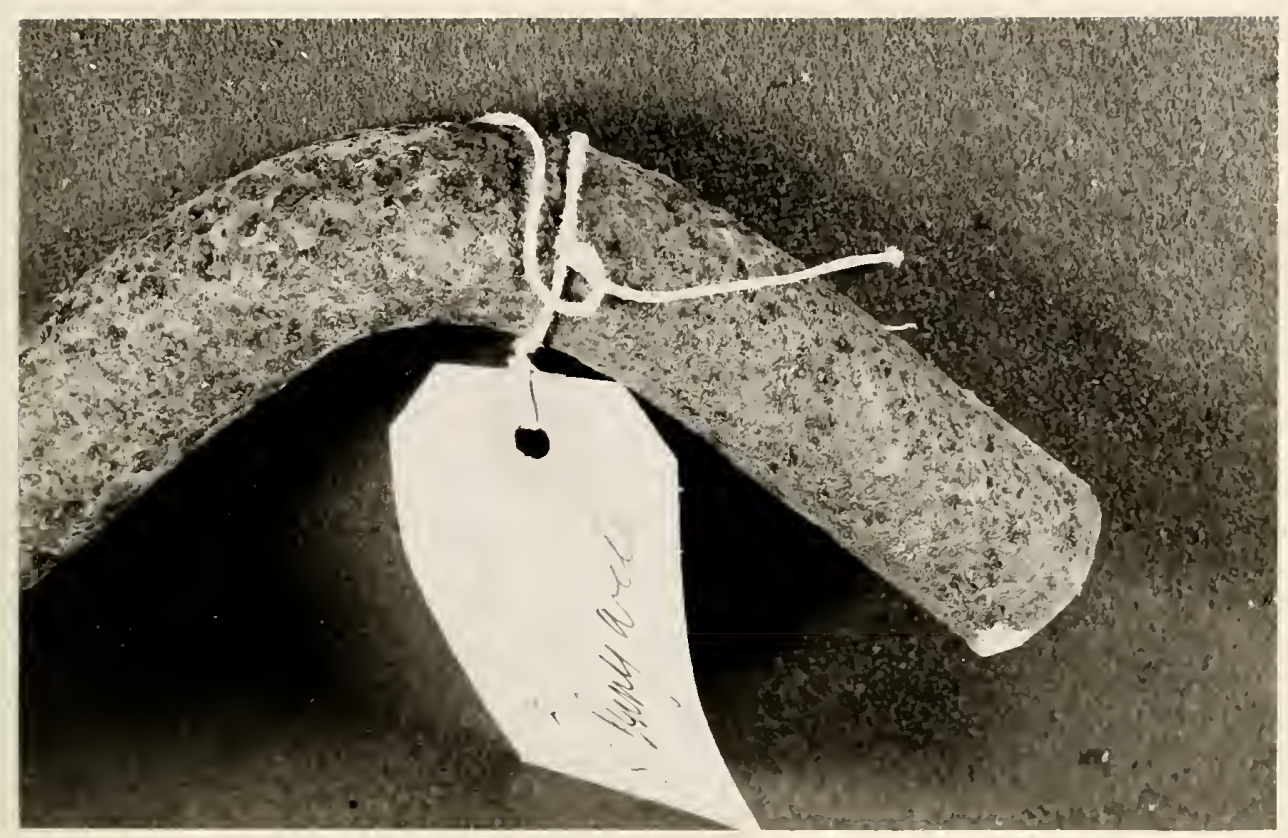

a

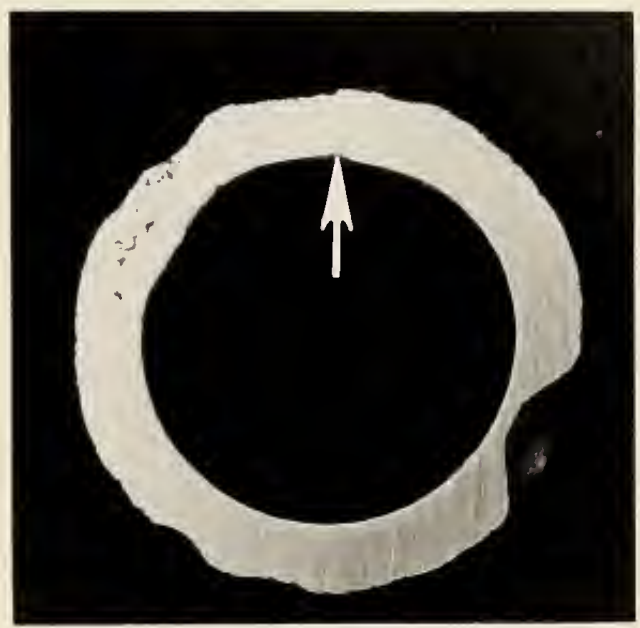

b

Figure 15. Pipe from $31 \mathrm{~S}$. Bennywell.

a. Bend region of pipe as received at NBS showing corrosion. $\mathrm{X} 1$

b. Cross section through one of the more severely corroded regions not in the bend. The dark areas between about 10 and $110^{\prime} \mathrm{clock}$ represent porosity. The welded seam is indicated by the arrow. 



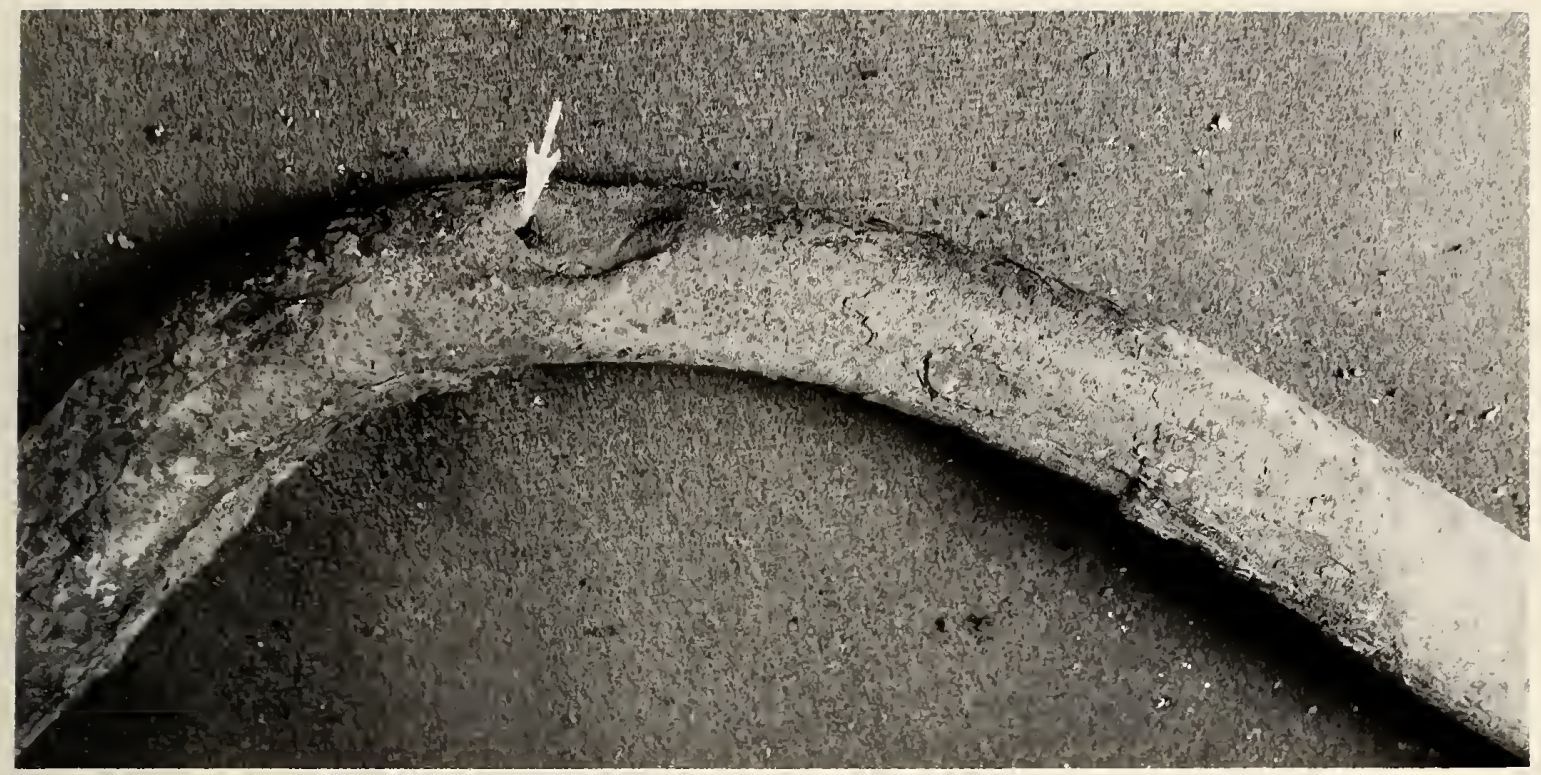

a

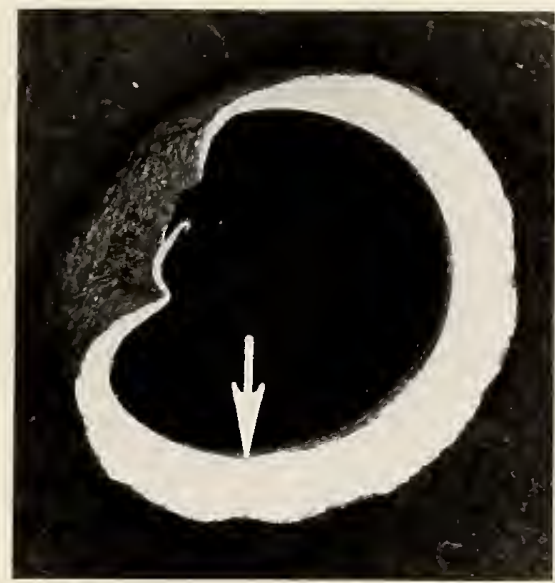

b

Figure 16. Pipe identified as 7.

a. Bend region of pipe as received at NBS showing corrosion, depression, and perforation (arrow).

b. Cross section through perforation showing extent of depression. Except for the depression, there is 1ittle evidence of cross sectional deformation in this figure. The welded seam is indicated by the arrow. 


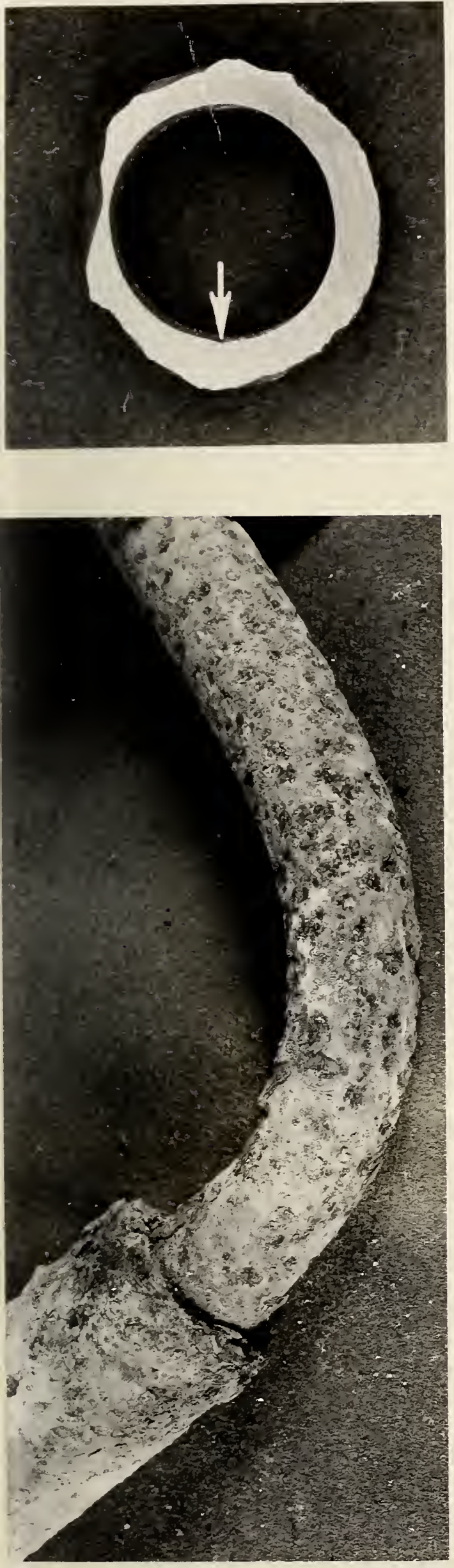

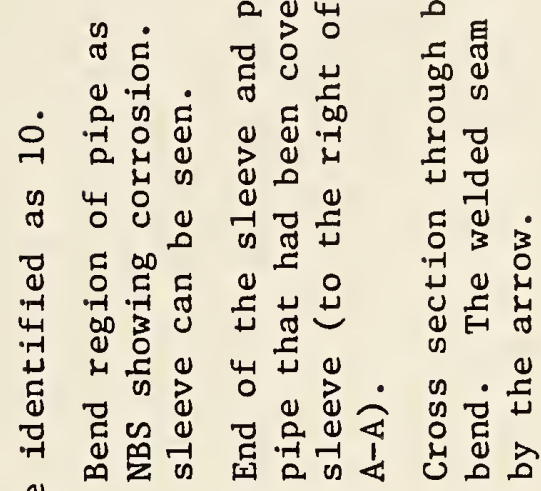

ت1

๙

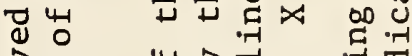

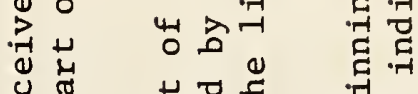

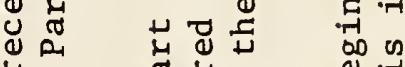

4 का का का

ค.

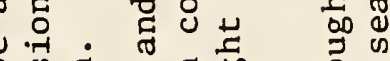

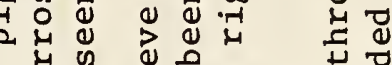

4

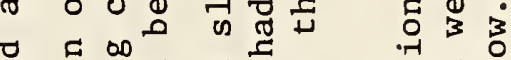

भ

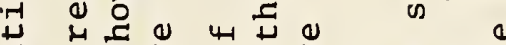

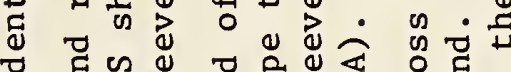

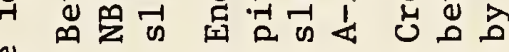

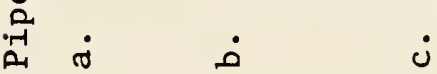
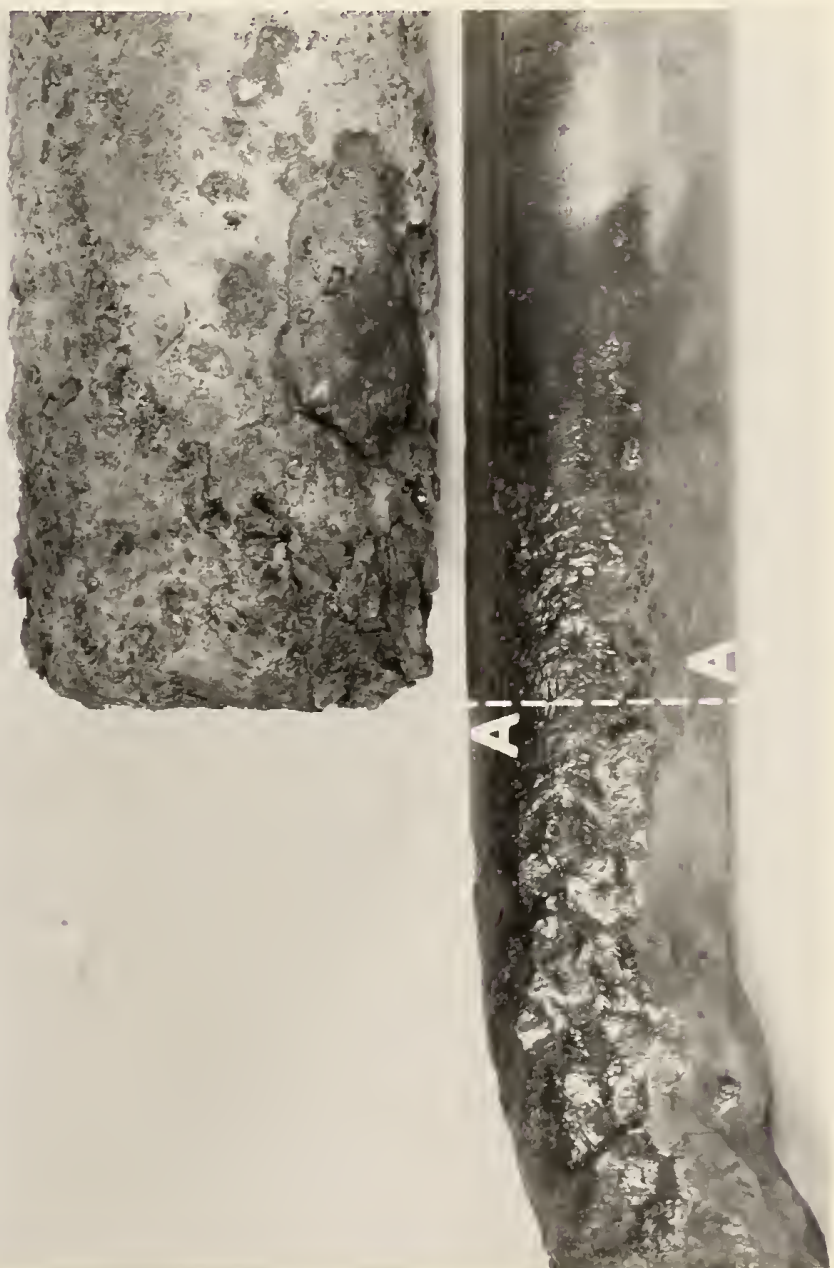



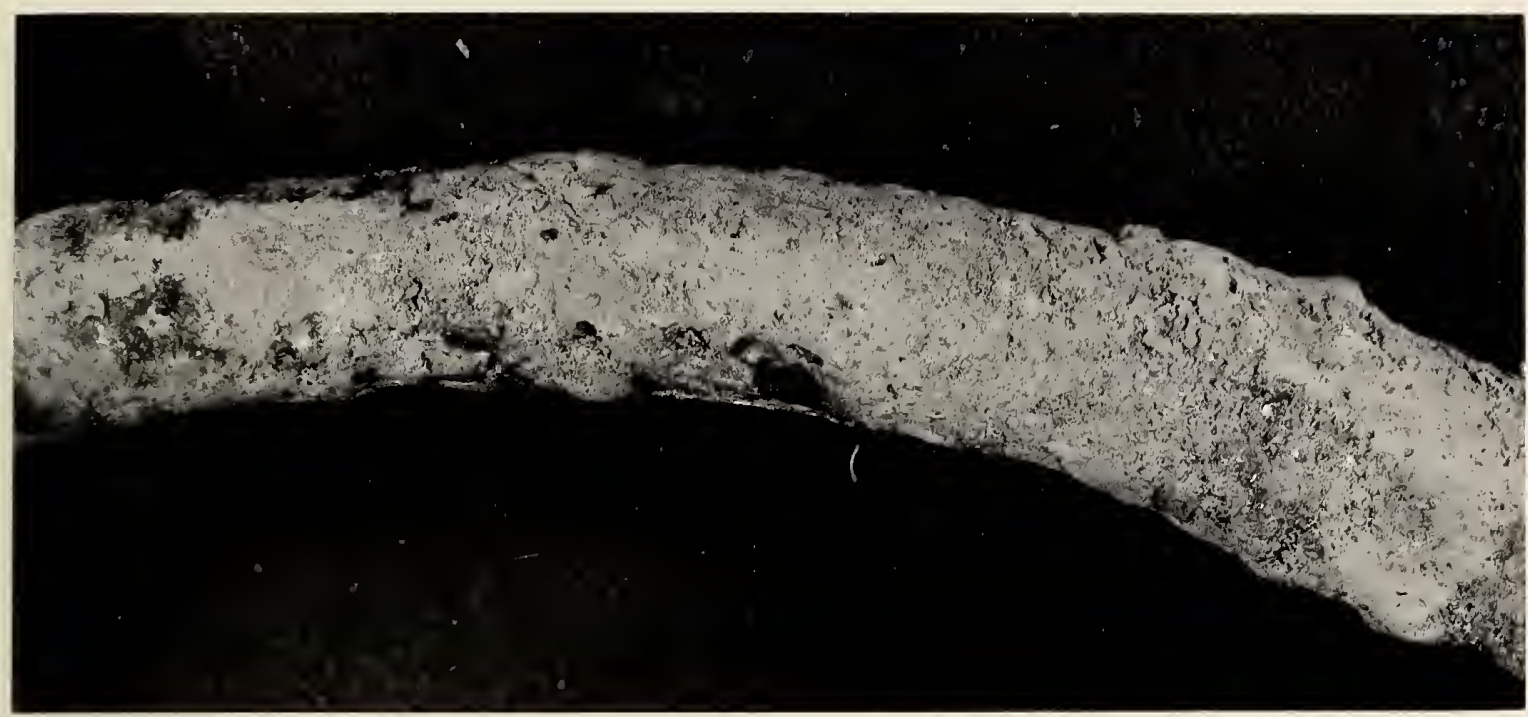

a

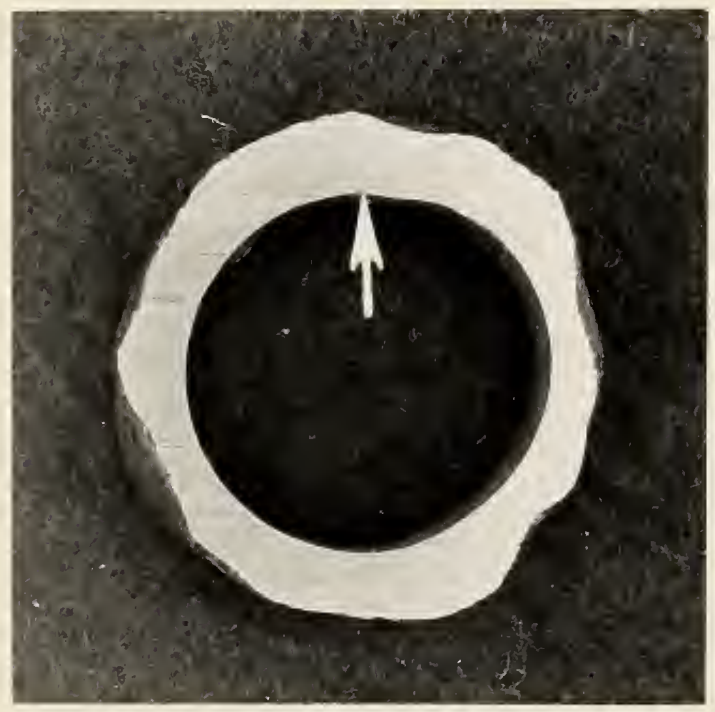

b

Figure 18. Pipe from $13 \mathrm{~s}$. Cannon Dr.

a. Bend region of pipe as received at NBS showing soil and corrosion. $\mathrm{X} 1$

b. Cross section through one of the more severely corroded regions adjacent to the bend. The welded seam is indicated by the arrow. $\mathrm{X} 2$ 



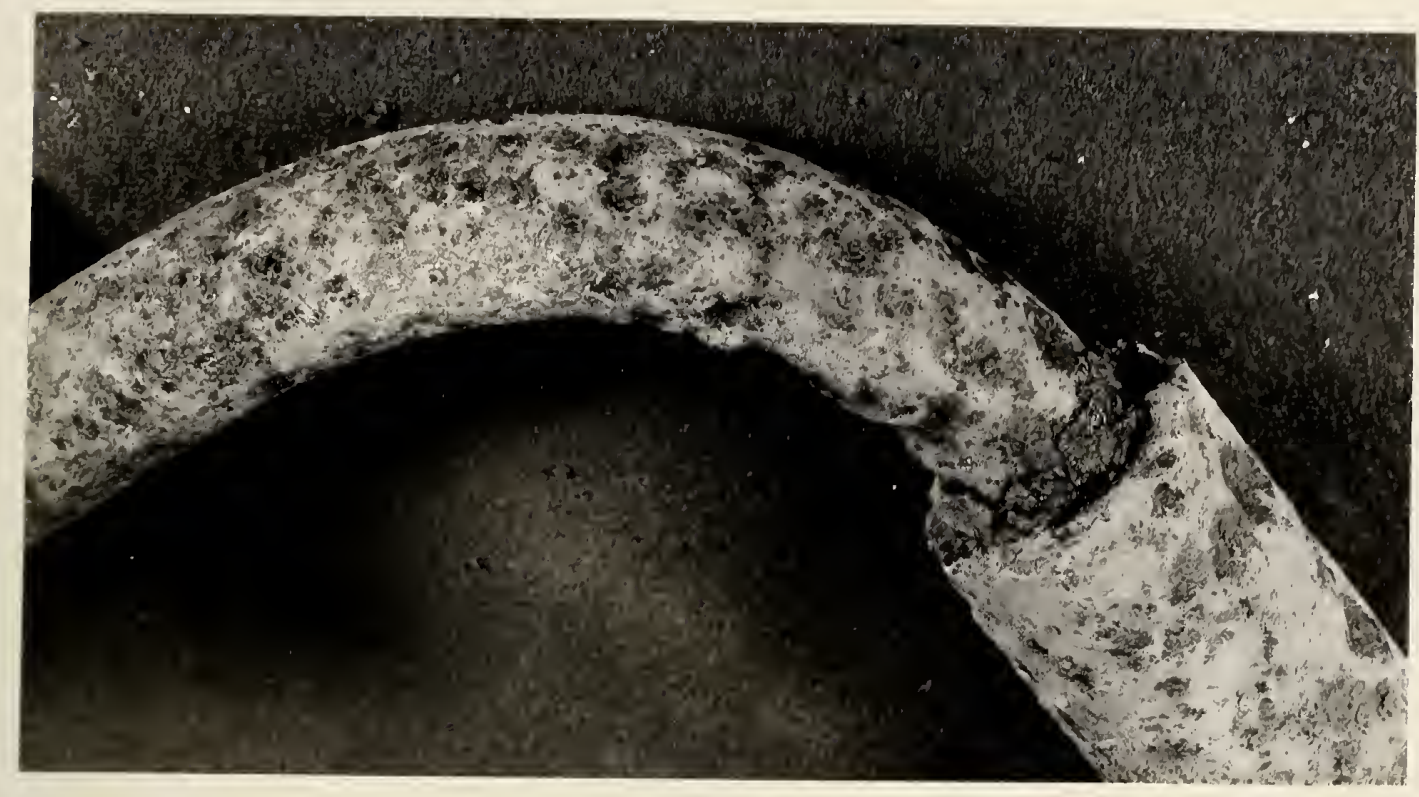

a

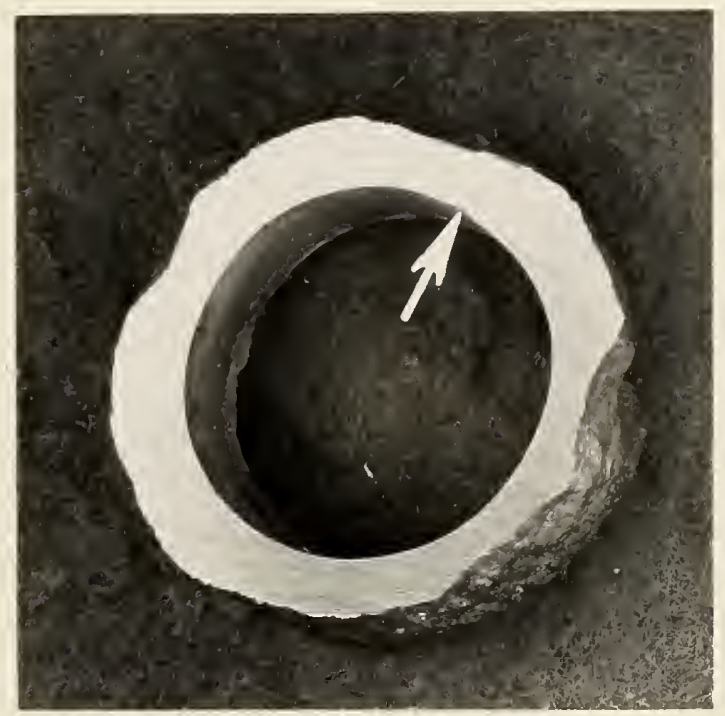

b

Figure 19. Pipe from $18 \mathrm{~S}$. Cannon.

a. Bend region of pipe as received at NBS showing corrosion. The end of a sleeve can be seen at the right.

X 1

b. Cross section through one of the more severely corroded regions of the bend. The welded seam is indicated by the arrow. 



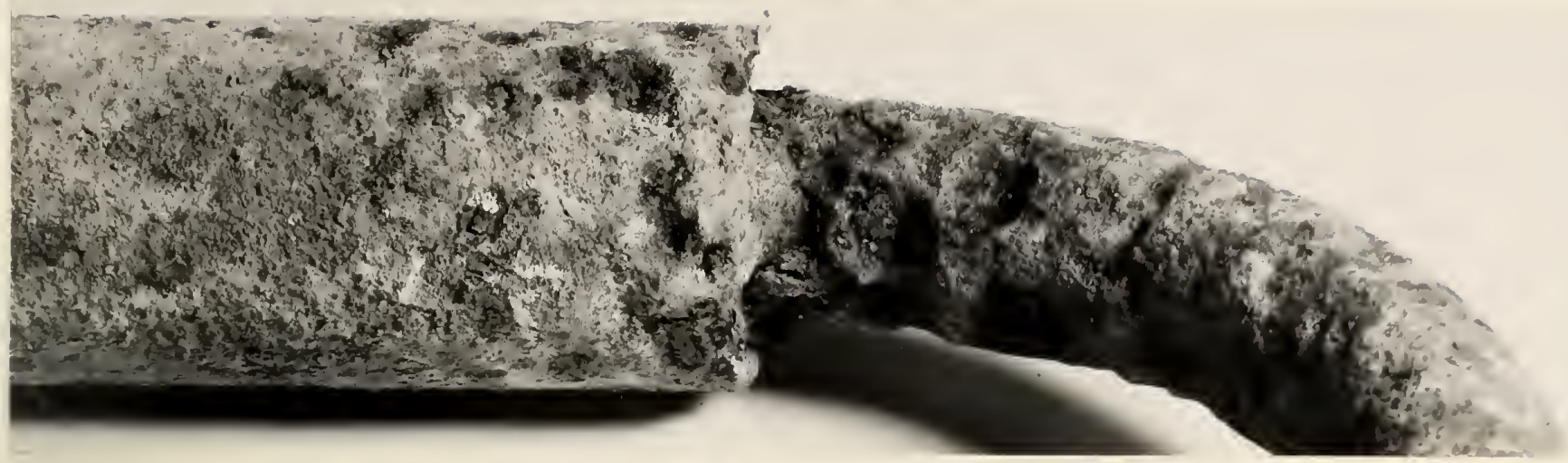

a

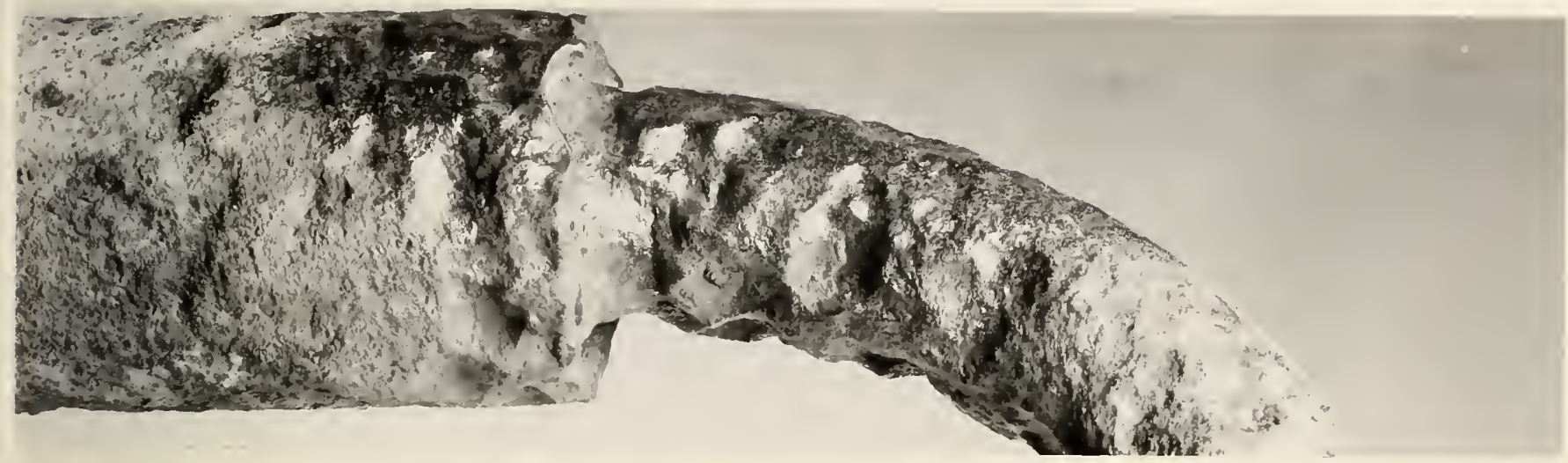

$\mathrm{b}$

Figure 20. Pipe from $18 \mathrm{~S}$. Cannon before and after cleaning. $\mathrm{X} 1$ a. Before cleaning.

b. After cleaning.

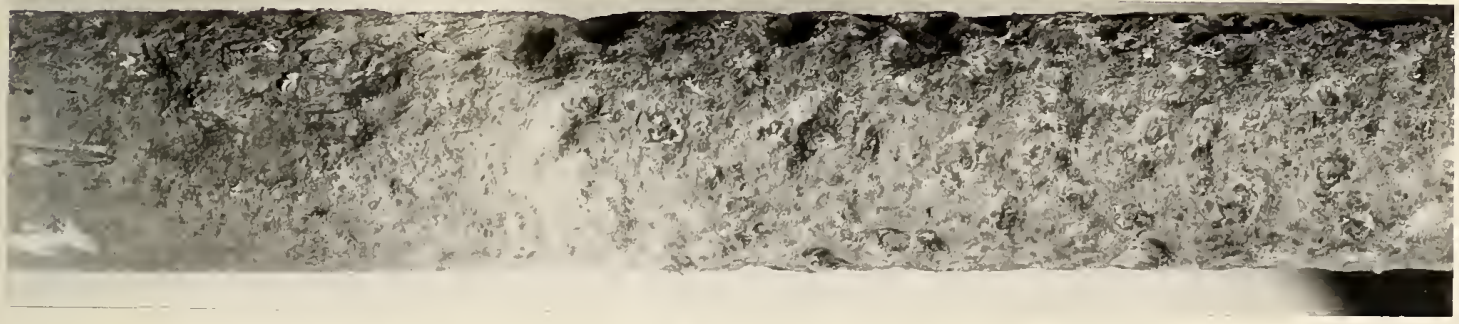

a

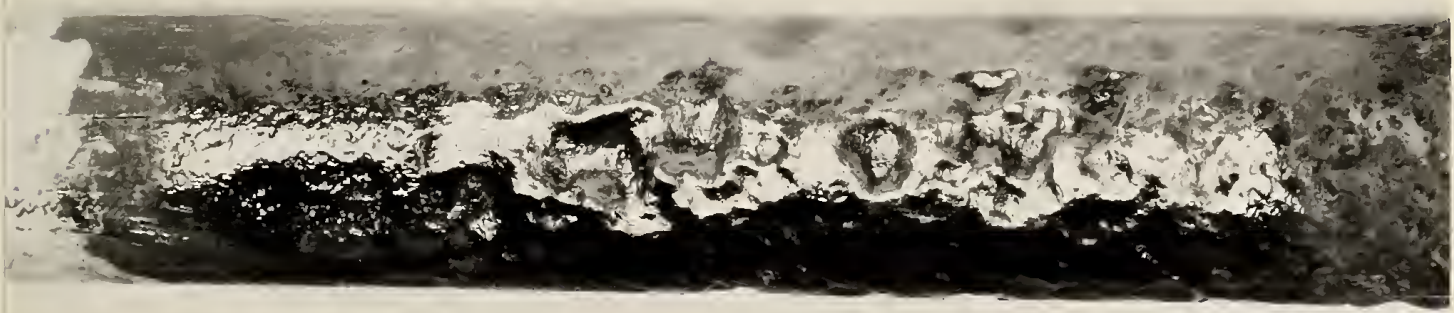

$\mathrm{b}$

Figure 21. Pipe from 31 S. Bennywell before and after cleaning. Pipe has been rotated slightly between figures a and b. X 1

a. Before cleaning.

b. After cleaning. 

Figure 22. As-polished cross section through the pipe from 8 clayton Ct. showing inclusion content representative of the sections examined.

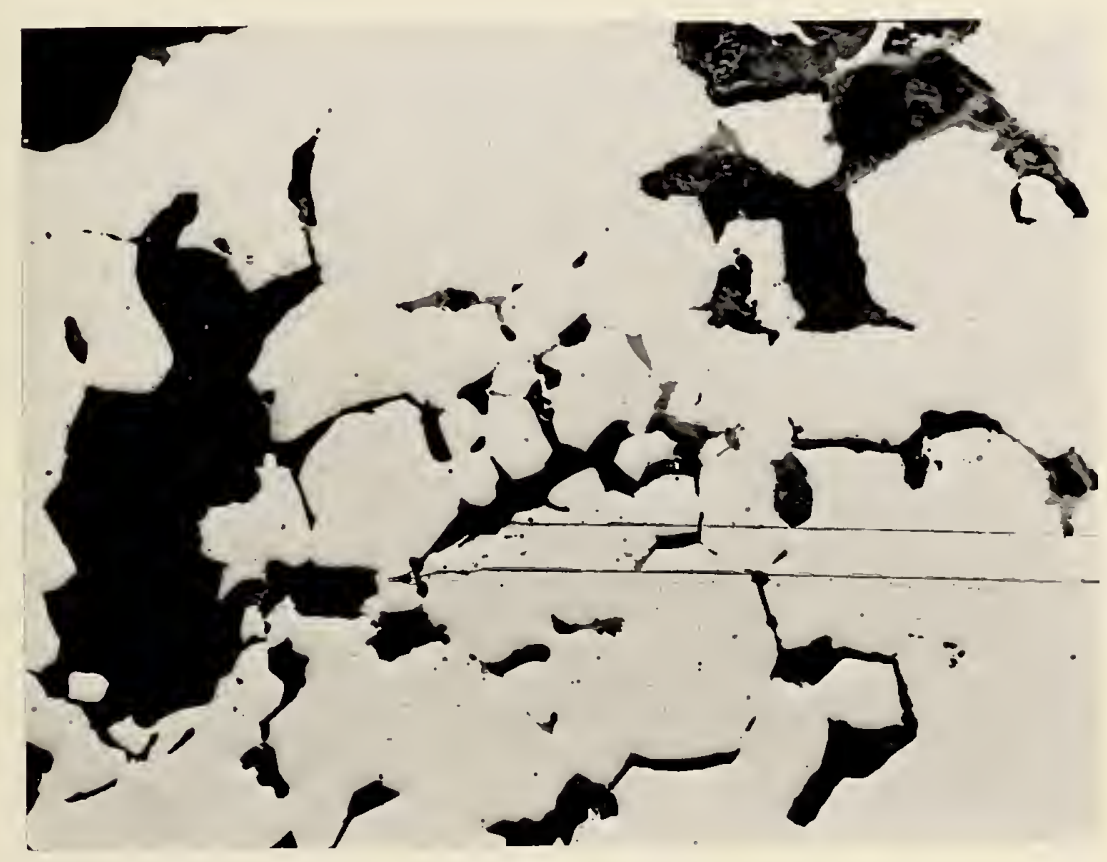

Figure 23. As-polished cross section through the pipe from $31 \mathrm{~S}$. Bennywel1 showing porosity. The location of the porosity in the pipe wall can be seen in figure 15b. The two parallel, nearly horizontal lines about $1 / 3$ the distance from the bottom of the figure are polishing scratches caused by foreign material being dragged from the pores. X 40 



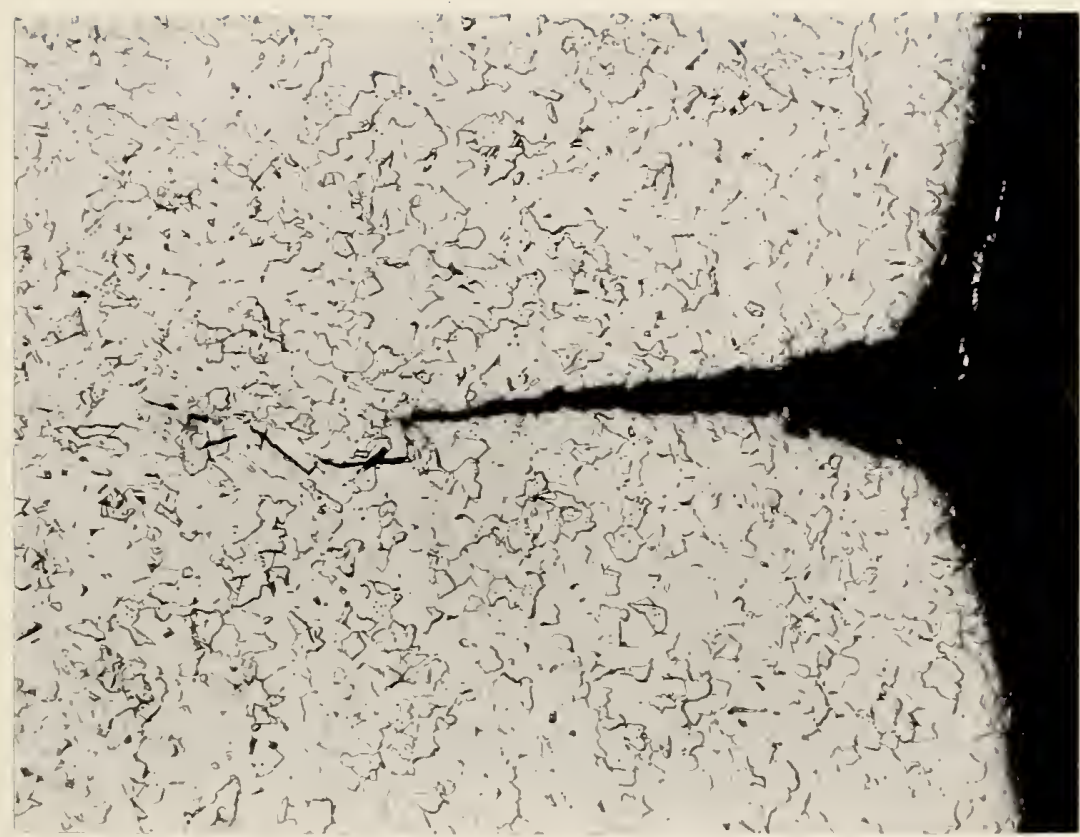

Figure 24. Etched cross section through the bend of the pipe sample from 8 clayton $\mathrm{Ct}$. showing cracking of the weld at the inside of the pipe. The inside wall surface of the pipe is vertical at the right.

Etchant: $1 \%$ nital

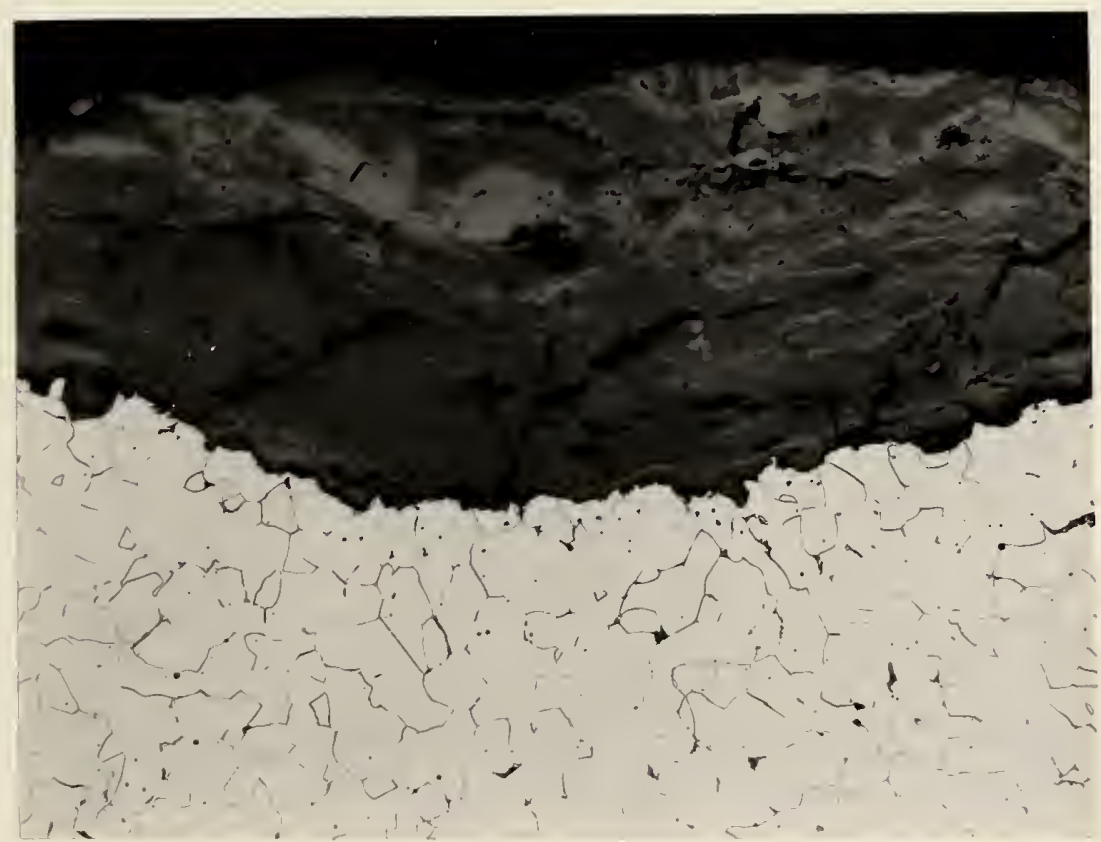

Figure 25. Etched cross section through pipe sample designated 10. The light gray material covering approximately the upper one-half of the figure is corrosion product. Etchant: $1 \%$ nital 



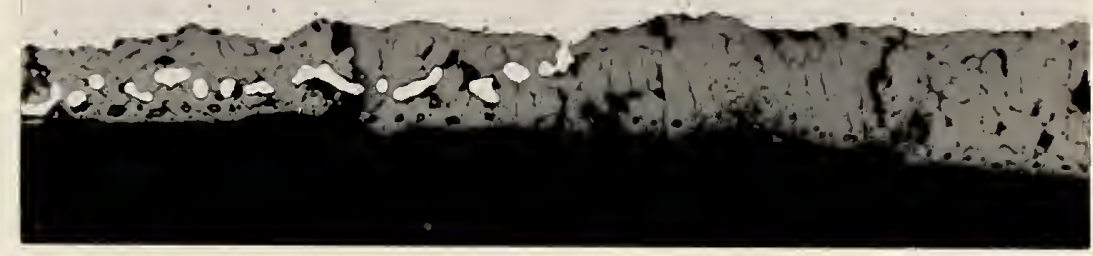

Figure 26. As-polished cross section through pipe sample from $31 \mathrm{~S}$. Bennywell showing corrosion product on the inside of the pipe. The corrosion product is light gray. X 100

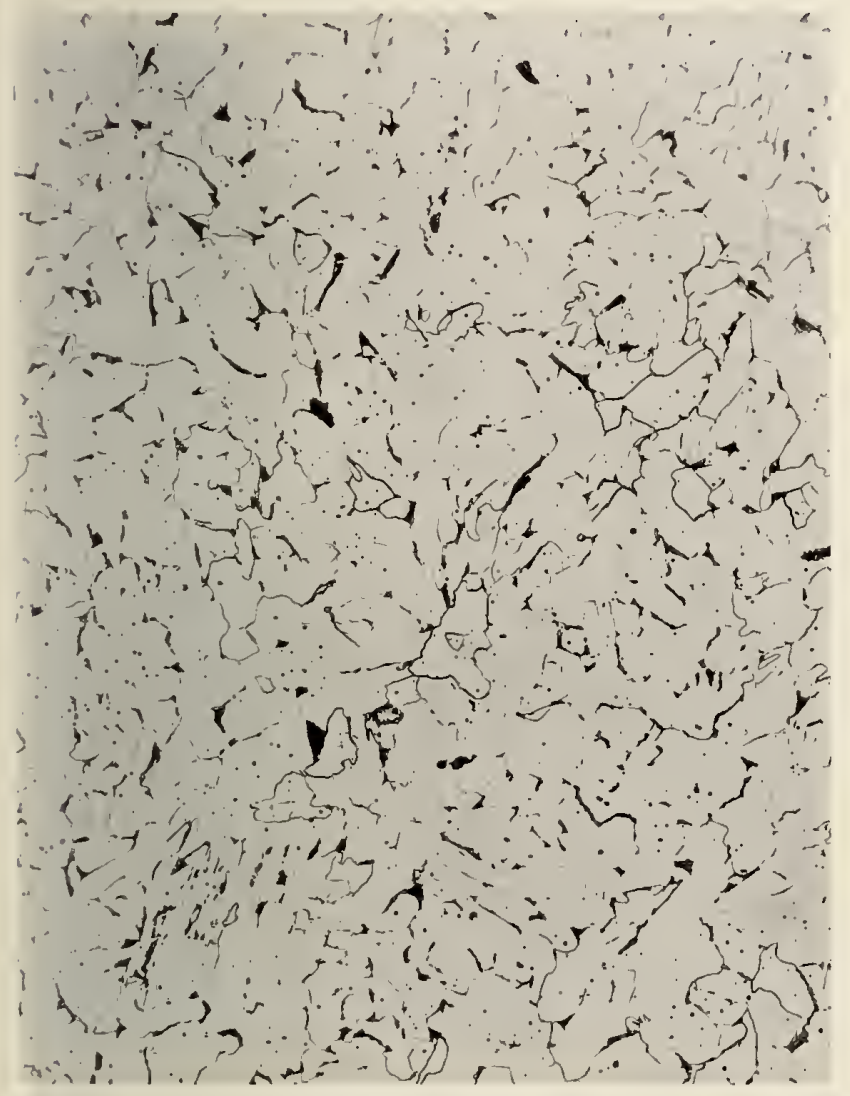

Figure 27. Etched cross section through pipe sample from 8 clayton $\mathrm{Ct}$. showing microstructure consisting of ferrite and a small amount of pearlite. Etchant: $1 \%$ nital X 100

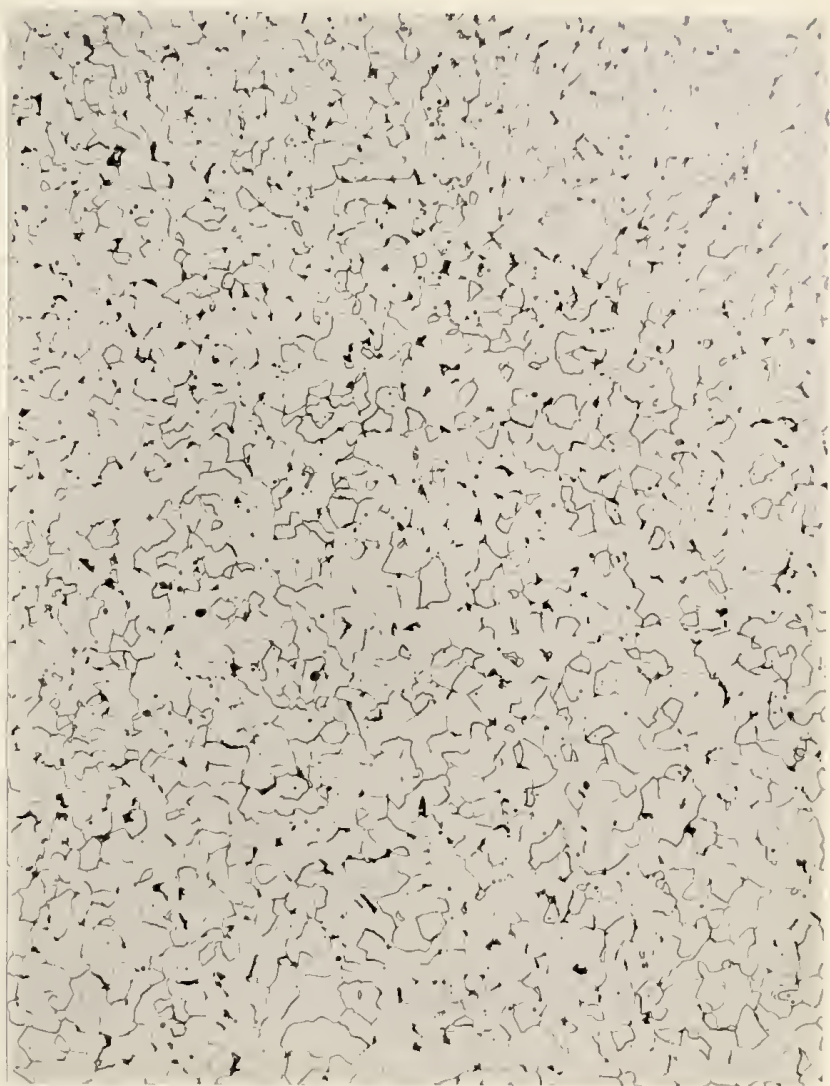

Figure 28. Etched cross section through pipe sample designated 7 showing microstructure consisting of ferrite and a small amount of pearlite. The grain size is smaller and the grains are more nearly equiaxed than in the microstructure shown in figure 27.

Etchant: $1 \%$ nital X 100 



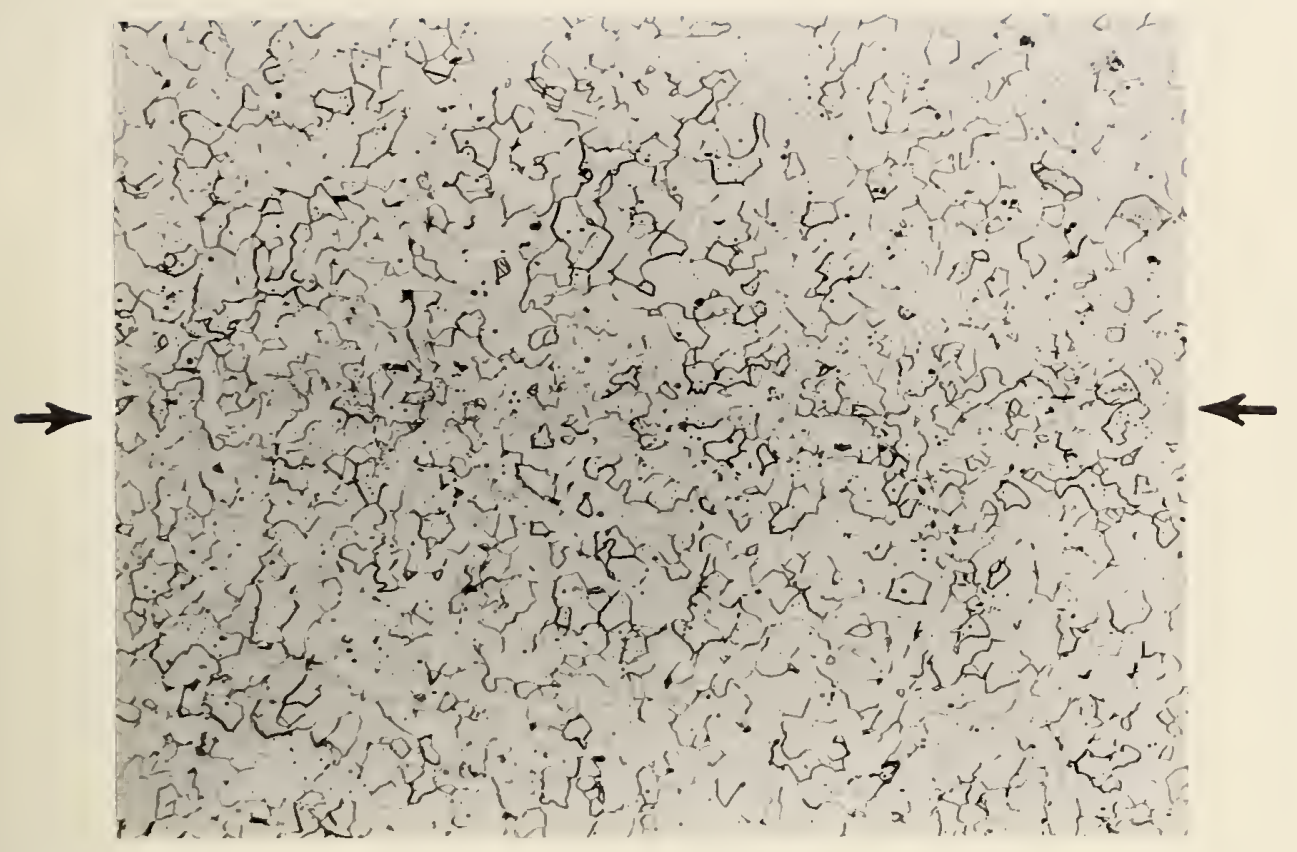

Figure 29. Etched cross section through pipe sample designated 10 showing the microstructure at the weld (between arrows) and on both sides of the weld.

Etchant: 1\% nital X 100

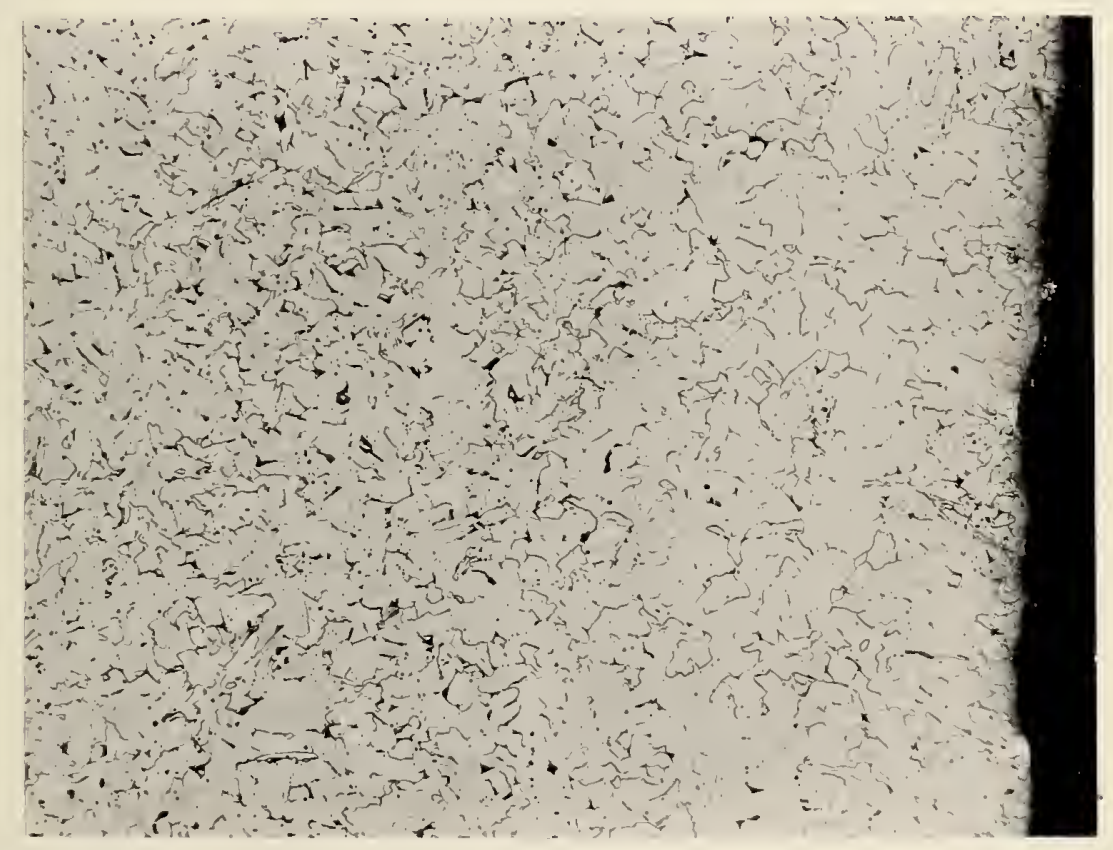

Figure 30. Etched cross section through pipe sample from 8 Clayton Ct. showing decarburization adjacent to the pipe surface (vertical at the right) in a slightly corroded region. Note that there are fewer of the small dark areas near the surface than in the left of the figure. Etchant: $1 \%$ nital 

NBS-114A (REV. 7-73)

\begin{tabular}{|c|c|c|c|}
\hline $\begin{array}{l}\text { U.S. OEPT. OF COMM. } \\
\text { BIBLIOGRAPHIC DATA } \\
\text { SHEET }\end{array}$ & $\begin{array}{l}\text { 1. PUBLLICATION OR REPORT NO. } \\
\text { NBSIR } 77-1198 \quad(\mathrm{R})\end{array}$ & $\begin{array}{l}\text { 2. Gov't Accession } \\
\text { No. }\end{array}$ & 3. Recipient's Accession No. \\
\hline \multirow{2}{*}{\multicolumn{3}{|c|}{$\begin{array}{l}\text { 4. TITLE AND SUBTITLE } \\
\text { EXAMINATION OF } 3 / 4 \text { INCH STEEL PIPE NATURAL GAS SERVICE } \\
\text { LINES, DELMARVA POWER AND LIGHT COMPANY, WILMINGTON, } \\
\text { DELAWARE }\end{array}$}} & 5. Publication Date \\
\hline & & & 6. Performing Organization Code \\
\hline \multicolumn{3}{|l|}{$\begin{array}{l}\text { 7. AUTHOR(S) } \\
\text { T. Robert Shives }\end{array}$} & $\begin{array}{l}\text { 8. Performing Organ. Report No. } \\
\text { NBSIR }\end{array}$ \\
\hline \multicolumn{3}{|c|}{$\begin{array}{l}\text { 9. PERFORMING ORGANIZATION NAME AND ADDRESS } \\
\text { NATIONAL BUREAU OF STANDARDS } \\
\text { DEPARTMENT OF COMMERCE } \\
\text { WASHINGTON, D.C. } 20234\end{array}$} & $\begin{array}{l}\text { 10. Project/Task/Work Unit No. } \\
3120418 \\
\text { 11. Contract/Grant No. }\end{array}$ \\
\hline \multirow{2}{*}{\multicolumn{3}{|c|}{$\begin{array}{l}\text { 12. Sponsoring Organization Name and Complete Address (Street, City, State, ZIP) } \\
\text { Office of Pipeline Safety Operations } \\
\text { Department of Transportation } \\
\text { Washington, D.C. } 20590\end{array}$}} & $\begin{array}{l}\text { 13. Type of Report \& Period } \\
\text { Covered } \\
\text { Failure Analysis Report }\end{array}$ \\
\hline & & & 14. Sponsoring Agency Code \\
\hline
\end{tabular}

15. SUPPLEMENTARY NOTES

16. ABSTRACT (A 200-word or less factual summary of most significant information. If document includes a significant bibliography or literature survey, mention it here.)

The Office of Pipeline Safety Operations requested that the NBS Mechanical Properties Section examine fourteen $3 / 4$ inch diameter steel pipe natural gas service lines from Edgemoor Gardens, Wilmington, Delaware. The submitted samples had all been installed in crawl spaces under houses. An explosion had been attributed to the ignition of gas leaking from one of these pipes. All of the pipe samples exhibited corrosion to some extent. Two samples, including the one reportedly involved in the explosion, had been perforated. Many others were severely corroded. A reportedly high concentration of water vapor in the poorly ventilated crawl spaces is suggested as the source of the corroding medium. Measurements in essentially uncorroded regions indicated that the original pipe wall thickness would meet current (1976) ASTM specifications. All but one of the longitudinal seam welds appeared to be in satisfactory condition. The unsatisfactory weld was cracked at a bend in the pipe where there was a considerable amount of cross sectional deformation. Several samples exhibited cross sectional deformation at the bend. The hardness and microstructure of the weld and parent materials appeared to be compatible. The microstructure of all the samples examined appeared to be satisfactory except for one sample that exhibited a large amount of porosity. All except the two perforated samples withstood a leak test at 30 psig natural gas.

17. KEY WORDS (six to twelve entries; alphabetical order; capitalize only the first letter of the first key word unless a proper name; separated by semicolons)

Corrosion; natural gas pipe; natural gas pipe failure; steel pipe.

18. AVAILABILITY Unlimited

X For Official Distribution. Do Not Release to NTIS sponsor is responsible for its further use.

$\square$ Order From Sup. of Doc., U.S. Government Printing Office Washington, D.C. 20402, SD Cat. No.C13

Order From National Technical Information Service (NTIS) Springfield, Virginia 22151
19. SECURITY CLASS (THIS REPURT)

UNCL ASSIF IED

20. SECURITY CLASS

(THIS PAGE)

UNCLASSIFIED
21. NO. OF PAGES

22. Price

(2) Price 
